Seminar Paper No. 128

THE THEORY OF TRADE IN MIDDLE PRODUCTS

by

Kalyan K. Sanyal

and

Ronald W. Jones

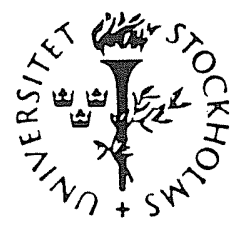

INSTITUTE FOR INTERNATIONAL ECONOMIC STUDIES

University of Stockholm 
ISSN $\quad 0347-8769$

Seminar Paper No. 128

THE THEORY OF TRADE IN MIDDLE PRODUCTS

by

Kalyan K. Sanyal

and

Ronald W. Jones

Seminar Papers are preliminary material circulated to stimulate discussion and critical comment. References in publications to Seminar Papers should be cleared with the author to protect the tentative character of these papers.

October, 1979

Institute for International Economic Studies

S-106 91 Stockholm

Sweden 


\title{
THE THEORY OF TRADE IN MIDDLE PRODUCTS
}

\author{
Kalyan K. Sanyal \\ and \\ Ronald W. Jones* \\ University of Rochester
}

The bulk of international commerce consists of trade in intermediate goods, raw materials, and goods which require further local processing before reaching the final consumer. Although this has become a common observation, it has yet to receive central attention in the pure theory of international trade. 0 A further observation is that few items in international trade are pure raw materials or primary factors which have not received any valueadded from other local inputs. Put together, these remarks suggest that in the typical productive spectrum whereby primary factors and labor help produce and transform commodities into the final state required by consumers, international trade takes place in "middle products".

The purpose of this article is to develop and analyze a model of international trade that recognizes as its central feature that the composition of the outputs of industrial activity at early stages need not match the composition of intermediate inputs at final stages of the productive spectrum. The first section of the paper reveals the features of the model by analyzing the resource shifts and cost changes as the ratio of final outputs changes along a transformation schedule. Sections II-VI proceed to apply the model to analyses of tariffs, changes in the terms of trade, technical

* This research was supported in part by a grant from the National Science Foundation Grant No. SOC78-06159. Typing services were generously supplied by the Institute for International Economic Studies, Stockholm.

0) Partial exception must be made for work in the theory of effective protection. 
progress, Eransfers, and exchange rate devaluation. Possible extensions are discussed at the end of the paper.

The model analyzed here builds upon two models standard in the trade literature, the Heckscher-Ohlin model with two mobile factors, and the specific factors model. It is considerably richer in structural detail than either of these precursors, and yet not much more difficult to analyze. It allows scope for the influence of demand, even for small countries which face world markets for traded "middle products". And it reveals how asymmetries between the productive structures of different countries - e.g. at different stages of the development process - might systematically lead to asymmetrical patterns of income redistribution as conditions of trade are altered. 


\section{The Mode1}

The key feature of the model is that international trade serves to demarcate all productive activity into two tiers: (i) In the Input Tier primary productive factors and labor produce commodities ("middle products") which enter into international trade and which are never consumed directly as final products. On the contrary, (ii) these middle products must each be combined with local labor in order to produce a final (non-traded) commodity in the Output Tier. Thus no trade takes place at the two ends of the productive spectrum. International trade allows the composition of the input mix into final consumer goods to differ from the proportions in which these middle products are produced in the Input Tier. Each productive tier is characterized by two distinct productive sectors, each employing labor and a factor, resource, or middle product specific to that sector. Labor is homogenous and mobile among all four sectors and, indeed, its endogenously determined allocation between productive tiers is a crucial determinant of the real wage.

\section{A. The Input Tier}

The Input Tier consists of a pair of sectors producing commodities (middle products) $\mathrm{x}_{A}$ and $\mathrm{x}_{\mathrm{B}}$. In the $\mathrm{x}_{\mathrm{j}}$ sector a fixed quantity of non-traded resource, $v_{j}$, is combined with labor to produce unique output $x_{j}$, For a given technology and a given allocation of labor to the input tier $\left(\mathrm{L}_{\mathrm{I}}\right)$ a strictly bowed-out transformation schedule can be constructed, as in Figure 1. If the world relative price of $\underline{A}$ is shown by the slope of line JH extended, production is given by point $\underline{J}$. 
I - $1 a$

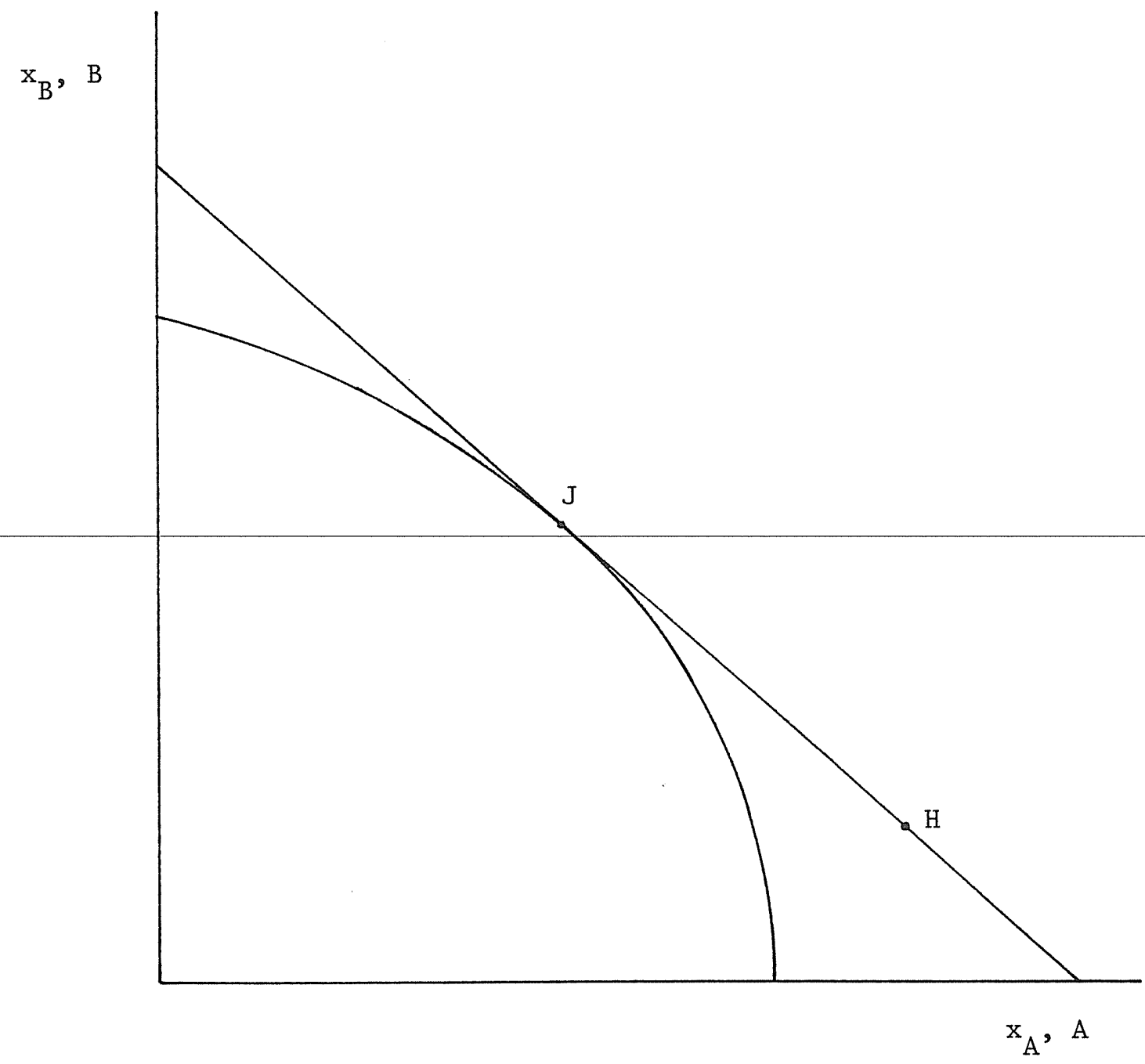

Figure 1 
The formal structure of production in the Input Tier is familiar from the literature on specific-factor models. ${ }^{1}$ Letting $a_{L j}$ represent the input coefficient of labor per unit output, the full utilization of the labor force alloted to the Input Tier $\left(\mathrm{L}_{\mathrm{I}}\right)$ is shown by equation (1):

(1) $a_{L A} x_{A}+a_{L B} x_{B}=L_{I}$.

Outputs of middle products are each linked to the available supply of specific factors $\left(V_{j}\right)$ and the intensity with which specific factors are utilized (shown by $a_{V A}$ and $a_{V B}$ ). Thus $a_{V A} x_{A}$ equals $v_{A}$ and $a_{V B} x_{B}$ equals $V_{B}$ - Substitute for these output levels in equation (1) and differentiate totally to obtain

$$
\lambda_{L A}\left(\hat{a}_{L A}-\hat{a}_{V A}\right)+\lambda_{L B}\left(\hat{a}_{L B}-\hat{a}_{V B}\right)=\hat{L}_{I}
$$

The $\lambda_{L j}$ are labor-allocation fractions (e.g. $\lambda_{L B}$ equals $L_{B} / L_{I}$ ) and a hat over a variable denotes relative changes (e.g. $\hat{\mathrm{L}}_{I}$ equals $\left.\mathrm{dL}_{I} / \mathrm{L}_{I}\right)$. Terms such as $\left(\hat{a}_{L A}-\hat{a}_{V A}\right)$, showing relative changes in factor proportions, can be linked by definition to the elasticity of factor substitution. Alternatively, and of more use in the Input Tier, they can be related to the elasticity of labor's marginal product curve in sector $j, \gamma_{j}$. For example,

$$
\gamma_{B} \equiv-\frac{\left(\hat{a}_{L B}-\hat{a}_{V B}\right)}{\left(\hat{w}-\hat{p}_{B}\right)},
$$

where $\mathrm{w} / \mathrm{p}_{\mathrm{B}}$ indicates the real wage in sector $\mathrm{B}$. Once these substitutions are made, the equation can be solved for the impact either

1) For example see Caves and Jones, [1], supplement to Chapter 6 . 
of price changes or labor supply changes on the wage rate. Thus:

$$
\begin{aligned}
& \hat{\mathrm{w}}=\beta_{\mathrm{A}} \hat{\mathrm{p}}_{\mathrm{A}}+\beta_{\mathrm{B}} \hat{\mathrm{p}}_{\mathrm{B}}-\frac{1}{\gamma_{I}} \hat{\mathrm{L}}_{I} \\
& \text { where } \beta_{\mathrm{A}} \equiv \frac{\lambda_{\mathrm{LA}} \gamma_{\mathrm{A}}}{\gamma_{I}} ; \beta_{\mathrm{A}}+\beta_{\mathrm{B}}=1 ; \\
& \text { and } \gamma_{\mathrm{I}} \equiv \lambda_{\mathrm{LA}} \gamma_{\mathrm{A}}+\lambda_{L B} \gamma_{\mathrm{B}} .
\end{aligned}
$$

Any increase in either $\mathrm{p}_{\mathrm{A}}$ or $\mathrm{p}_{\mathrm{B}}$ results in a fractional relative increase in the wage rate if the labor allocation between tiers is set. However, at given prices the wage rate is driven up if labor leaves the Input Tier. $\gamma_{I}$ reflects this 1ink. An exogenous increase in the wage rate of $1 \%$ would cause the Input Tier's aggregate demand for labor to fall by $\gamma_{I} \%$.

The Input Tier's transformation schedule shown in Figure 1 is drawn as of a fixed allocation of labor between tiers. Let $\mathrm{T}$ denote the value of middle-product output:

$$
\mathrm{T} \equiv \mathrm{p}_{\mathrm{A}} \mathrm{x}_{\mathrm{A}}+\mathrm{p}_{\mathrm{B}} \mathrm{x}_{\mathrm{B}}=\mathrm{w}_{\mathrm{I}}+\mathrm{r}_{\mathrm{A}} \mathrm{V}_{\mathrm{A}}+\mathrm{r}_{\mathrm{B}} \mathrm{v}_{\mathrm{B}}
$$

where $r_{j}$ is the rental return on specific factor $V_{j}$. Since $V_{A}$ and $V_{B}$ are fixed, for movements along Figure $I^{\prime}$ 's transformation schedule,

$$
\mathrm{p}_{\mathrm{A}} \mathrm{dx}_{\mathrm{A}}+\mathrm{p}_{\mathrm{B}} \mathrm{dx}_{\mathrm{B}}=0
$$

which corresponds at point $J$ with the fact that the slope of the transformation schedule is given by the price ratio. However, this schedule shifts inwards if $\mathrm{L}_{\mathrm{I}}$ contracts, with the value of the shift per unit labor at constant prices given by the wage rate:

$$
w=\left.\frac{\partial T}{\partial \mathrm{L}_{\mathrm{I}}}\right|_{\overline{\mathrm{p}}_{\mathrm{A}}, \overline{\mathrm{p}}_{\mathrm{B}}}
$$


Such an inward shift must reduce outputs of both middle products. Whether $\mathrm{L}_{I}$ expands or contracts depends in large part on the productive structure in the Output Tier.

\section{B. The Output Tier}

The Output Tier bears a strong similarity to the Input Tier in that again two sectors each draw labor from a common market to combine with an input used only in that sector in order to produce a single output. These outputs now represent final (non-traded) goods yielding direct utility to consumers. Thus traded middle product $\mathrm{A}$ is combined with labor to produce $\mathrm{x}_{1}$ and middle product $\mathrm{B}$ input is specifically used in producing $\mathrm{x}_{2}$. Consumer tastes are defined over final commodities 1 and 2 and help determine their prices, even in a small economy that must take prices of traded middle products, $\mathrm{p}_{\mathrm{A}}$ and $\mathrm{p}_{\mathrm{B}}$, as given by the outside world.

The basic dissimilarity between the two tiers is that a given output of $\mathrm{x}_{A}$ and $\mathrm{x}_{\mathrm{B}}$ from the Input Tier need not freeze the "endowments" of A and B available to producers in the Output Tier since international trade allows production to differ from (derived) demand. The tangent line in Figure 1 reflects given world prices, $\mathrm{p}_{\mathrm{A}}$ and $\mathrm{p}_{\mathrm{B}}$, and, at these prices, optimal production of $\mathrm{x}_{\mathrm{A}}$ and $\mathrm{x}_{\mathrm{B}}$ remains at $\mathrm{J}$ for a prescribed allocation of labor between tiers. Demand for middle products might be at some other point, say $\underline{\text { H}}$. Furthermore, the proportions of middle products demanded by the economy will vary with the composition of final outputs $x_{1}$ and $x_{2}$.

To compound matters, the quantity of labor available in the Output Tier $\left(\mathrm{L}_{0}\right)$ itself is endogenous $1 \mathrm{y}$ dependent upon the desired proportions in which final goods $x_{1}$ and $x_{2}$ are produced. The 
I $-4 a$

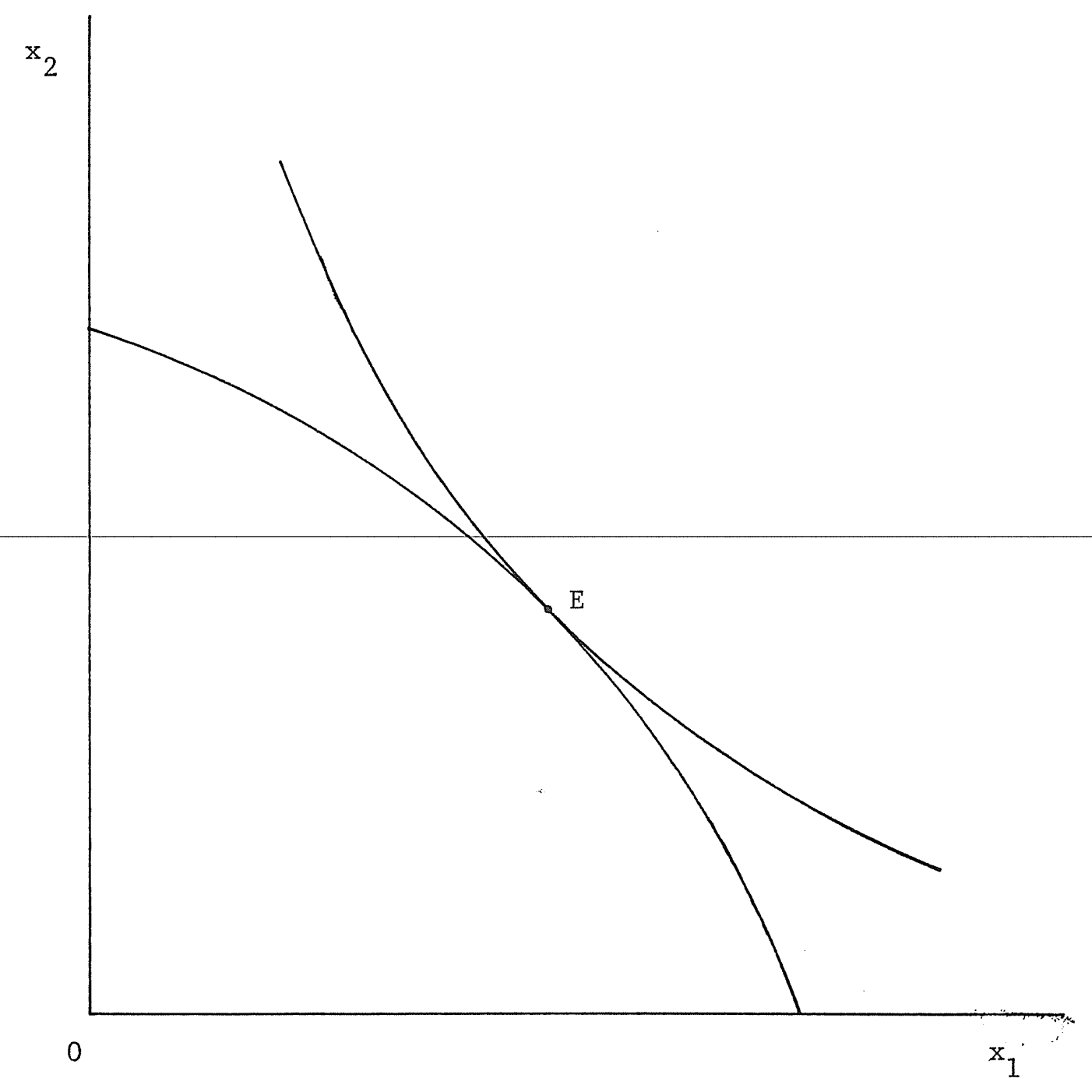

Figure 2 
"transformation curve" in Figure 2, which together with consumer tastes determines final consumption point $\underline{E}$ (with the relative $p_{1} / p_{2}$ price ratio shown by the mutual slope at $\underline{E}$ ), is not based upon fixed "endowments" of $\mathrm{A}, \mathrm{B}$ and $\mathrm{L}_{0}$. Rather, it presumes the balance of trade constraint and an allocation of labor between tiers that yields over-all full employment of a given labor force, $\overline{\mathrm{L}}$, at a common wage rate:

$$
\mathrm{L}_{\mathrm{I}}+\mathrm{L}_{0}=\overline{\mathrm{L}}
$$

Figure 3 can be used to trace through these behind-the-scenes re-allocations. Suppose point $\underline{\mathrm{C}}$ represents an initial full equilibrium. Through-point $\underline{\underline{E}}$ two-downward-sloping straight lines-have been drawn, each corresponding to the set of factor prices and inter-tier labor allocation at initial point $\underline{\mathrm{C}}$. One of these lines $\left(\mathrm{L}_{0}\right)$ corresponds to the labor constraint in the Output Tier:

$$
a_{L 1} x_{1}+a_{L 2} x_{2}=L_{0} \text {. }
$$

The second linear constraint is derived from Figure 1's trading line and the fixed value of the economy's derived demand for traded middle products for given prices and inter-tier labor allocation. The input of $A$ into producing $x_{1}$ is the per-unit requirement, ${ }_{A 1}$, times output level $x_{1}$. Similarly, $B$, the economy's derived demand for middle product $B$, equals $a_{B 2} x_{2}$. The balance of trade constraint requires

$$
\left(\mathrm{p}_{\mathrm{A}} \mathrm{a}_{\mathrm{A} 1}\right) \mathrm{x}_{1}+\left(\mathrm{p}_{\mathrm{B}} \mathrm{a}_{\mathrm{B} 2}\right) \mathrm{x}_{2}=\mathrm{T},
$$

where $\mathrm{T}$ is the value of output in the Input Tier. With appropriate relabeling, this constraint is written as:

(4) $\mathrm{a}_{\mathrm{T} 1} \mathrm{x}_{1}+\mathrm{a}_{\mathrm{T} 2} \mathrm{x}_{2}=\mathrm{T}$ 
The rationale behind these substitutions lies in a reconceptualization of the productive structure in the Output Tier. Although $\underline{A}$ and $\underline{B}$ are separate middle products used specifically in the production of $x_{1}$ and $x_{2}$, the assumption that they can be exchanged in world markets at given prices allows them to be lumped together in a Hicksian composite input or factor, which we have called $\underline{T}$. This allowable aggregation serves, as we show below, to transform the structure of the specific factor Output Tier into the standard $2 \times 2$ mobile factor Heckscher-Ohlin structure. Free trade in world markets for middle products $\underline{A}$ and $\underline{B}$ substitutes completely for their sectoral specificity in-producing $x_{1}$ and $x_{2}$.

By drawing the labor constraint in Figure 3 steeper than the constraint imposed by the given value ( $T$ ) of middle products available through trading the outputs from the Input Tier, we have incorporated the (arbitrary) assumption that commodity 1 is 1aborintensive compared with commodity 2. Given this assumption it is clear that if an increase in $x_{1}$-production is desired from point $\underline{C}$ in Figure 3, the direct labor constraint from a given value of $\mathrm{L}_{0}$ pinches more tightly than does the constraint provided by the availability of traded middle products given allocation of $\mathrm{L}_{I}$ to the Input Tier. This allows a release of labor from the Input Tier to the Output Tier. In Figure 1 this would serve to shrink the Input Tier's transformation schedule towards the origin and, with it, the amounts of $\underline{A}$ and $\underline{B}$ available through trade at fixed prices. Thus in Figure 3 the T-line shifts towards the origin and the release of labor thus provided is shown by the $\mathrm{L}_{0}-1$ ine shifting outwards. The new intersection point is $\underline{D}$. 


$$
I-\bar{\varnothing}
$$

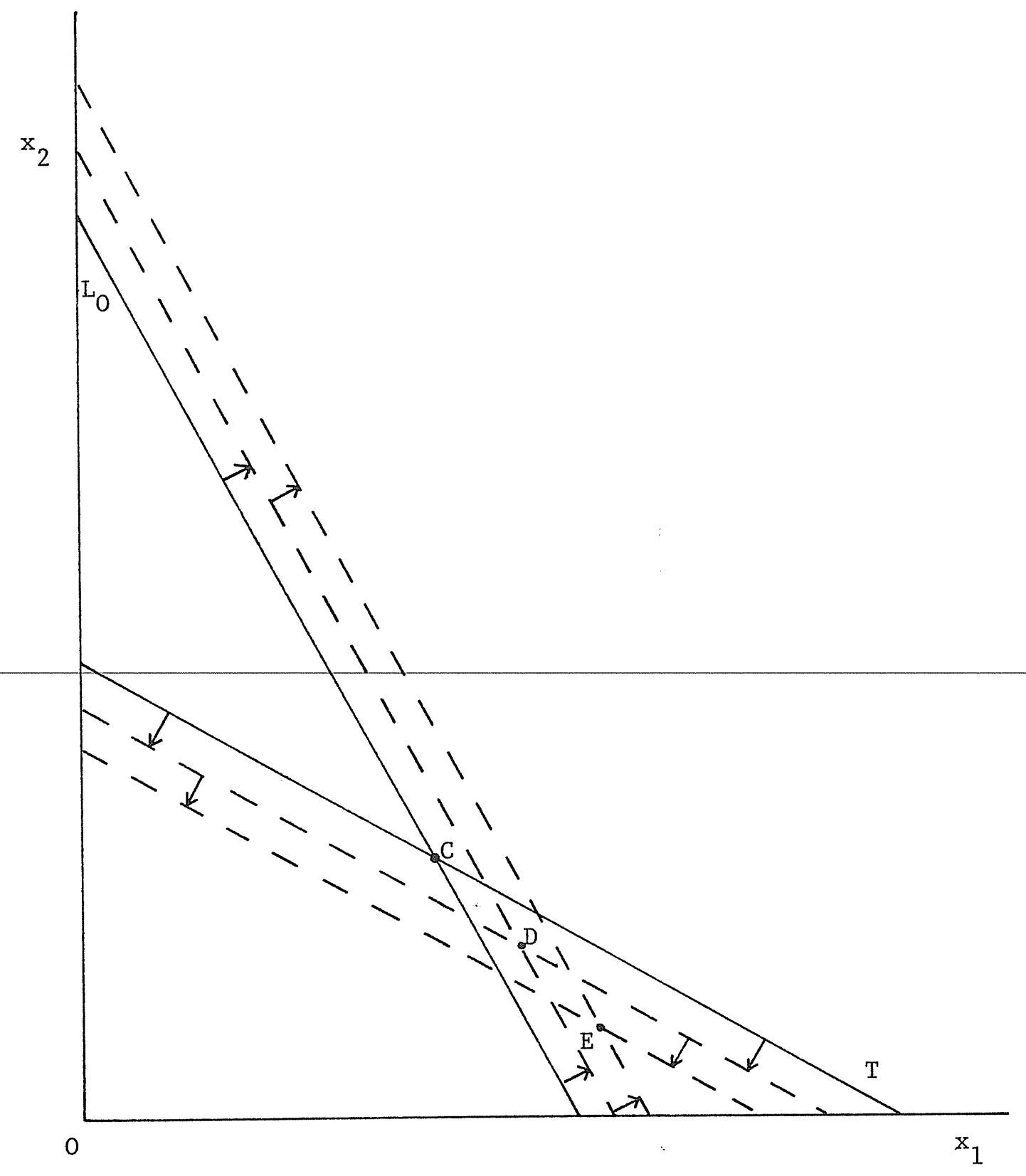

Figure 3 
These shifts in the constraint lines shown in Figure 3 refer explicitly to the direct transfer of labor from the Input Tier to the Output Tier. But the constraints are further affected by the consequent change in factor prices and the substitution in productive techniques they call forth. As we show explicitly below, these changes involve: (a) A rise in the wage rate relative to fixed traded goods prices as labor leaves the Input Tier; (b) A fall in the rentals on factors specifically employed in producing middle product outputs $\mathrm{x}_{A}$ and $\mathrm{x}_{B}$; (c) A less intensive use of labor throughout the economy. In particular, $\mathrm{a}_{\mathrm{L} 1}$ and $\mathrm{a}_{\mathrm{L} 2}$ are reduced, causing the $\mathrm{L}_{0}$-constraint line to shift even further outwards; and (d) A more intensive use of middle product inputs as wages rise. That is, $a_{\mathrm{T} 1}$ and $\mathrm{a}_{\mathrm{T} 2}$ rise in equation (4), causing the T-constraint line to fall even further towards the origin. Point $\underline{E}$ in Figure 3 shows the resultant new output composition of non-tradables. Thus the $x_{1}-x_{2}$ transformation schedule (not drawn in Figure 3) passes through points $\underline{C}$ and $\underline{E}$.

To proceed formally, differentiate equations (3) and (4) to obtain (5) and (6):

$$
\begin{aligned}
& \lambda_{\mathrm{L} 1} \hat{\mathrm{x}}_{1}+\lambda_{\mathrm{L} 2} \hat{\mathrm{x}}_{2}=\hat{\mathrm{L}}_{0}-\left\{\lambda_{\mathrm{L} 1} \hat{\mathrm{a}}_{\mathrm{L} 1}+\lambda_{\mathrm{L} 2} \hat{\mathrm{a}}_{\mathrm{L} 2}\right\} \\
& \text { (6) } \lambda_{\mathrm{T} 1} \hat{\mathrm{x}}_{1}+\lambda_{\mathrm{T} 2} \hat{\mathrm{x}}_{2}=\hat{\mathrm{T}}-\left\{\lambda_{\mathrm{T} 1} \hat{\mathrm{a}}_{\mathrm{T} 1}+\lambda_{\mathrm{T} 2} \hat{\mathrm{a}}_{\mathrm{T} 2}\right\}
\end{aligned}
$$

Now $\lambda_{i j}$ denotes the fraction of factor $i$ available to the Output Tier used in the $j \underline{t h}$ industry. For example, $\lambda_{L 2}$ is the fraction of the Output Tier's labor force used in the second industry. The right hand side of equations (5) and (6) reveals the two ways in which the restraints on final outputs can be altered. A reallocation of labor between tiers affects $L_{0}$ and $T$ in opposite directions. And input-output coefficients depend upon changes in input prices. 
For example, in the first industry, ${ }^{2}$

$$
\begin{aligned}
& \hat{\mathrm{a}}_{\mathrm{L} 1}=-\theta_{\mathrm{T} 1} \sigma_{1} \hat{\mathrm{w}} \\
& \hat{\mathrm{a}}_{\mathrm{T} 1}=\theta_{\mathrm{L} 1} \sigma_{1} \hat{\mathrm{w}}
\end{aligned}
$$

where $\theta_{i 1}$ represents factor i's distributive share in the first industry, $\sigma_{1}$ is the elasticity of substitution and $\underline{w}$ is the wage rate. Define

$$
\delta_{\mathrm{L}} \equiv \lambda_{\mathrm{L} 1} \theta_{\mathrm{T} 1} \sigma_{1}+\lambda_{\mathrm{L} 2} \theta_{\mathrm{T} 2} \sigma_{2}
$$

and $\delta_{\mathrm{T}} \equiv \lambda_{\mathrm{T} 1} \theta_{\mathrm{L} 1} \sigma_{1}+\lambda_{\mathrm{T} 2} \theta_{\mathrm{I} 2} \sigma_{2}$,

so that (5) and (6) can be rewritten as (7) and (8).

(8) $\lambda_{\mathrm{T} 1} \hat{\mathrm{x}}_{1}+\lambda_{\mathrm{T} 2} \hat{\mathrm{x}}_{2}=\hat{\mathrm{T}}-\delta_{\mathrm{T}} \hat{\mathrm{w}}$

If the allocation of labor between tiers were frozen, output changes in (7) and (8) would be related precisely as in the standard $2 \times 2$ Heckscher-Ohlin mode1. ${ }^{3}$ The extra dimension present in this model is the endogeneity of labor's allocation between tiers. Equation (2) shows how, at constant world price for middle products

2) These solutions follow from two relationships: Since costs are minimized along the unit isoquant, $\theta_{\mathrm{L} 1} \hat{a}_{\mathrm{L} 1}+\theta_{\mathrm{T} 1} \hat{a}_{\mathrm{T} 1}=0$. And, by the definition of the elasticity of substitution between labor and good $A$ in the first industry, $\hat{a}_{L 1}-\hat{a}_{T 1}$ equals minus $\sigma_{1}$ times $\left(\hat{w}-\hat{\mathrm{p}}_{\mathrm{A}}\right)$. In the present exercise, $\hat{\mathrm{p}}_{\mathrm{A}}$ is zero.

3) See, for example, the treatment in Caves and Jones [1], Supplement to Chapter 7, or Jones, [3], Chapter 4. 
$\underline{A}$ and $\underline{B}$, the quantity of labor allocated to the Input Tier depends upon the wage rate. Thus $\hat{\mathrm{L}}_{I}$ equals minus $\gamma_{I} \hat{\mathrm{w}}_{\text {. From the overa11 }}$ full employment condition,

(9) $\lambda_{L I} \hat{\mathrm{L}}_{\mathrm{I}}+\lambda_{\mathrm{LO}} \hat{\mathrm{L}}_{\mathrm{O}}=0$, where $\lambda_{L I}$ and $\lambda_{L 0}$ reflect the fractional division of the labor force between tiers. Thus with constant traded goods prices,

$$
\hat{\mathrm{L}}_{0}=\frac{\lambda_{\mathrm{LI}} \gamma_{I}}{\lambda_{\mathrm{LO}}} \hat{\mathrm{w}}
$$

Referring back to equation (5), any increase in the wage rate not only causes both non-traded sectors to use labor less intensively (thus relaxing the labor constraint on $x_{1}$ and $x_{2}$ production), but also attracts labor to the Output Tier.

In equation (6) $\hat{\mathrm{T}}$ refers to the relative change in the aggregate value of output in the Input Tier at constant world prices for middle products. $T$ is reduced if labor leaves the Input Tier. Since the wage rate itself shows the decrease in output value of $\mathrm{T}$ for a unit loss of labor, in relative terms we have:

$$
\hat{\mathrm{T}}=\theta_{\mathrm{LI}} \hat{\mathrm{L}}_{\mathrm{I}} \text {, }
$$

where $\theta_{\text {LI }}$ denotes the distributive share which labor receives in the Input Tier. The allocation of labor is, in turn, linked to changes in the wage rate so that:

$$
\hat{\mathrm{T}}=-\theta_{L I} \gamma_{I} \hat{\mathrm{w}}
$$

With these solutions for $\hat{\mathrm{L}}_{0}$ and $\hat{\mathrm{T}}$, equation (8) can be subtracted from equation ( 7 ) to obtain: 


$$
|\lambda|\left(\hat{x}_{1}-\hat{x}_{2}\right)=\left(\frac{\lambda L I}{\lambda_{L O}}+\theta_{L I}\right) \dot{\gamma}_{I} \hat{w}+\left(\delta_{L}+\delta_{T}\right) \hat{w}
$$

where $|\lambda|$ refers to the determinant of coefficients in (5) and (6) and equals $\left(\lambda_{\mathrm{L} 1}-\lambda_{\mathrm{T} 1}\right)$. It is a fraction, positive if, as we are assuming, non-traded good 1 is labor-intensive. The expression $\left(\frac{\lambda_{L I}}{\lambda_{L O}}+\theta_{L I}\right)$ can more simply be stated as the ratio $\theta_{L I} / \theta_{L O}$, a comparison of the distributive shares of labor in the two tiers. Thus:

$$
\left(\hat{x}_{1}-\hat{x}_{2}\right)=\left\{\frac{\delta_{L}+\delta_{T}+\frac{{ }^{\theta} L I}{\theta_{L O}} \gamma_{I}}{|\lambda|}\right\} \hat{w}
$$

An increase in the wage rate accompanies an increase in the relative output of non-traded good $x_{1}$ along the transformation schedule if good 1 is labor-intensive.

The slope of the $x_{1}-x_{2}$ transformation schedule once labor reallocations are taken into account must reflect the relative price of good $1, \mathrm{p}_{1} / \mathrm{p}_{2}$. It remains to analyze the link between the relative price of non-traded goods and the distribution of income, especially the wage rate. Once this connection is found, equation (10) can explicitly show the elasticity of substitution between non-traded commodities along the transformation schedule. of course the question of income distribution is important in its own right, as subsequent sections applying the model emphasize.

The competitive profit conditions for non-tradeables require changes in unit costs, distributive-share averages of input price changes, to equal the relative changes in output prices:

$$
\begin{aligned}
& \text { (11) }{ }_{\mathrm{L} 11} \hat{\mathrm{w}}+\theta_{\mathrm{A} 1} \hat{\mathrm{p}}_{\mathrm{A}}=\hat{\mathrm{p}}_{1} \\
& \text { (12) } \theta_{\mathrm{L} 2} \hat{\mathrm{w}}+\theta_{\mathrm{B} 2} \hat{\mathrm{p}}_{\mathrm{B}}=\hat{\mathrm{p}}_{2}
\end{aligned}
$$


If, as we are now assuming, traded goods prices, $\mathrm{p}_{\mathrm{A}}$ and $\mathrm{p}_{\mathrm{B}}$, are being held constant,

$$
|\theta| \hat{\mathrm{w}}=\left(\hat{\mathrm{p}}_{1}-\hat{\mathrm{p}}_{2}\right)
$$

where $|\theta|$ refers to the fraction, $\left(\theta_{L 1}-\theta_{L 2}\right)$. Since commodity 1 is assumed to be labor-intensive, $|\theta|$ is positive, and an increase in $I^{\prime}$ 's relative price serves (as already noted) to attract labor from the Input Tier, thus driving up the wage rate.

A strong pattern of internal income distribution characteristic of Heckscher-Ohlin models emerges. Suppose $\mathrm{p}_{\mathrm{A}}$ and $\mathrm{p}_{\mathrm{B}}$ are constant, but that output of good 1, the labor-intensive-good, isexpanded along the transformation schedule. Then

$$
\hat{\mathrm{w}}>\hat{\mathrm{p}}_{1}>\hat{\mathrm{p}}_{2}>\hat{\mathrm{p}}_{\mathrm{A}}=\hat{\mathrm{p}}_{\mathrm{B}}=0>\text { both } \hat{\mathrm{r}}_{\mathrm{A}} \text { and } \hat{\mathrm{r}}_{\mathrm{B}} \text {. }
$$

Such an expansion of labor-intensive non-tradeables is "inflationary" in the sense of raising prices of both final non-tradeable goods. Labor unambiguously gains, a reflection of the strong magnification effect in a model which has the properties of a Heckscher-Ohlin $2 \times 2$ model although inputs $\underline{A}$ and $\underline{B}$ are specific. Factors specifically employed with labor in the Input Tier unambiguously lose, with the relative extent of their loss depending upon labor shares in the Input Tier.

Finally, in equation (10) substitute for the wage rate change to obtain equation (13) as the link between relative outputs of non-tradeables and relative output prices:

$$
\left(\hat{x}_{1}-\hat{x}_{2}\right)=\left\{\frac{\delta_{L}+\delta_{T}+\frac{{ }^{\theta} L I}{\theta_{L O}} \gamma_{I}}{|\lambda||\theta|}\right\}\left(\hat{p}_{1}-\hat{p}_{2}\right)
$$


The expression in the denominator must be positive regardless of the factor intensity ranking (assuming intensities differ), so that the transformation schedule between non-traded outputs, with the behind-the-scenes reallocation of labor between tiers taken into account, must be bowed out. Figure 2 shows how local taste patterns for non-tradeables help determine the final equilibrium point $\underline{E}$.

Expression (13) shows how the elasticity of substitution along the Output Tier's transformation schedule is larger than would be the corresponding expression in a Heckscher-Ohlin model with two mobile factors ( $L$ and $T$ ) but with a fixed supply of labor $\left(\mathrm{L}_{\mathrm{o}}\right)$ and therefore also of $\mathrm{T} .{ }^{4}$ With reference to Figure 4, suppose the economy is in full equilibrium at point $\underline{\mathrm{C}}$. Locus (ii) would show the response of outputs to changes in $\mathrm{p}_{1} / \mathrm{p}_{2}$ if trade in middle products is allowed but the allocation of labor between tiers is frozen. Schedule (i) would show the response of outputs if, in addition, the composition of middle product inputs $\underline{A}$ and $\underline{B}$ is kept rigid at the value it possesses at point $\underline{\mathrm{C}}$. A curve like (ii) is an envelope of curves such as (i), much as Mayer in [5] showed that a transformation schedule with freely mobile capital (occupationally) is an envelope of short-run transformation schedules with specific capital. The yet more elastic response shown by (iii) captures the reallocation of labor from the Input Tier to the Output Tier as labor-intensive commodity $x_{1}$ is expanded.

4) That is, in such a Heckscher-Ohlin model the elasticity of substitution along the transformation schedule equals $\frac{\delta_{L}+\delta_{T}}{|\lambda||\theta|}$.

See, for example, Jones, [3], chapter 4.". 
$I-12 a$

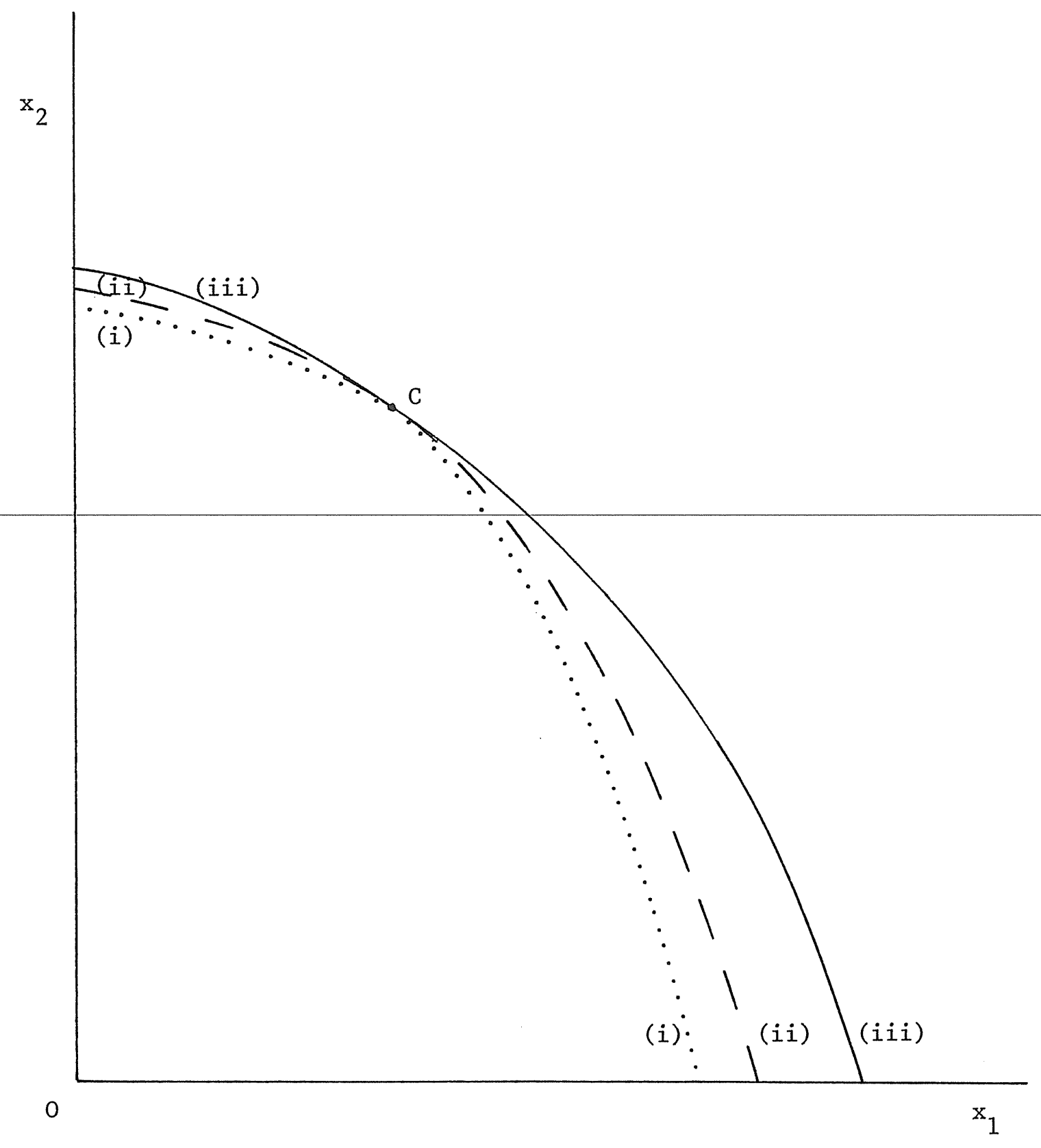

Figure 4 


\section{The Pattern of Trade}

So far little has been said about the pattern of trade. As of given world prices for tradeable middle products, the pattern of trade depends upon the equilibrium established by local taste patterns for non-tradeables and technology in the Output Tier (point $\underline{E}$ in Figure 2) as well as technology and resource endowments in the Input Tier (establishing point $\mathrm{J}$ in Figure 1).

Consider traded middle product $\underline{A}$ and ask how local (derived) demand for $\underline{A}$ and production, $\dot{x}_{A}$, change as $\mathrm{p}_{1} / \mathrm{p}_{2}$ increases from low to high values along the $x_{1}-x_{2}$ transformation schedule. Since world prices of $A$ and $B$ are fixed, Figure 1 shows that production, $\mathrm{x}_{\mathrm{A}}$, depends only upon the quantity of labor allocated to the Input Tier, $\mathrm{L}_{\mathrm{I}}$. As $\mathrm{p}_{1} / \mathrm{p}_{2}$ rises, the wage rate is driven up if, as assumed, the first commodity is labor-intensive. This increase in the wage rate can only be supported in the Input Tier if labor leaves, thus raising the ratio of specific factors to labor and allowing labor's marginal product to rise. The $\mathrm{x}_{\mathrm{A}}{ }^{-\mathrm{x}_{\mathrm{B}}}$ transformation schedule in Figure 1 would thus contract and, at constant prices, production of both middle products would be reduced. This is captured explicitly in Figure 5 by the downward slope of the $\mathrm{x}_{\mathrm{A}}$ schedule.

The community's demand for middle product $\underline{A}$ is derived from its production of final (non-tradeable) commodity 1 . As $\mathrm{p}_{1} / \mathrm{p}_{2}$ rises so does $\mathrm{x}_{1}$ along the transformation schedule.

Demand for $\underline{A}$ is the product of $x_{1}$ and the intensity with which $\underline{A}$ is used in $x_{1}$ production, shown by $a_{A 1}$. If good 1 is labor-intensive, an increase in $\mathrm{p}_{1} / \mathrm{p}_{2}$ serves to drive the wage rate up, relative to the fixed price of $\underline{A}$. Thus a ${ }_{\mathrm{A} 1}$ rises (스 is used more intensively) and the product, ${ }^{a} 1_{1} x_{1}$, must unambiguously rise. This supports the rising A-schedule in Figure 5. 


$$
I-13 a
$$

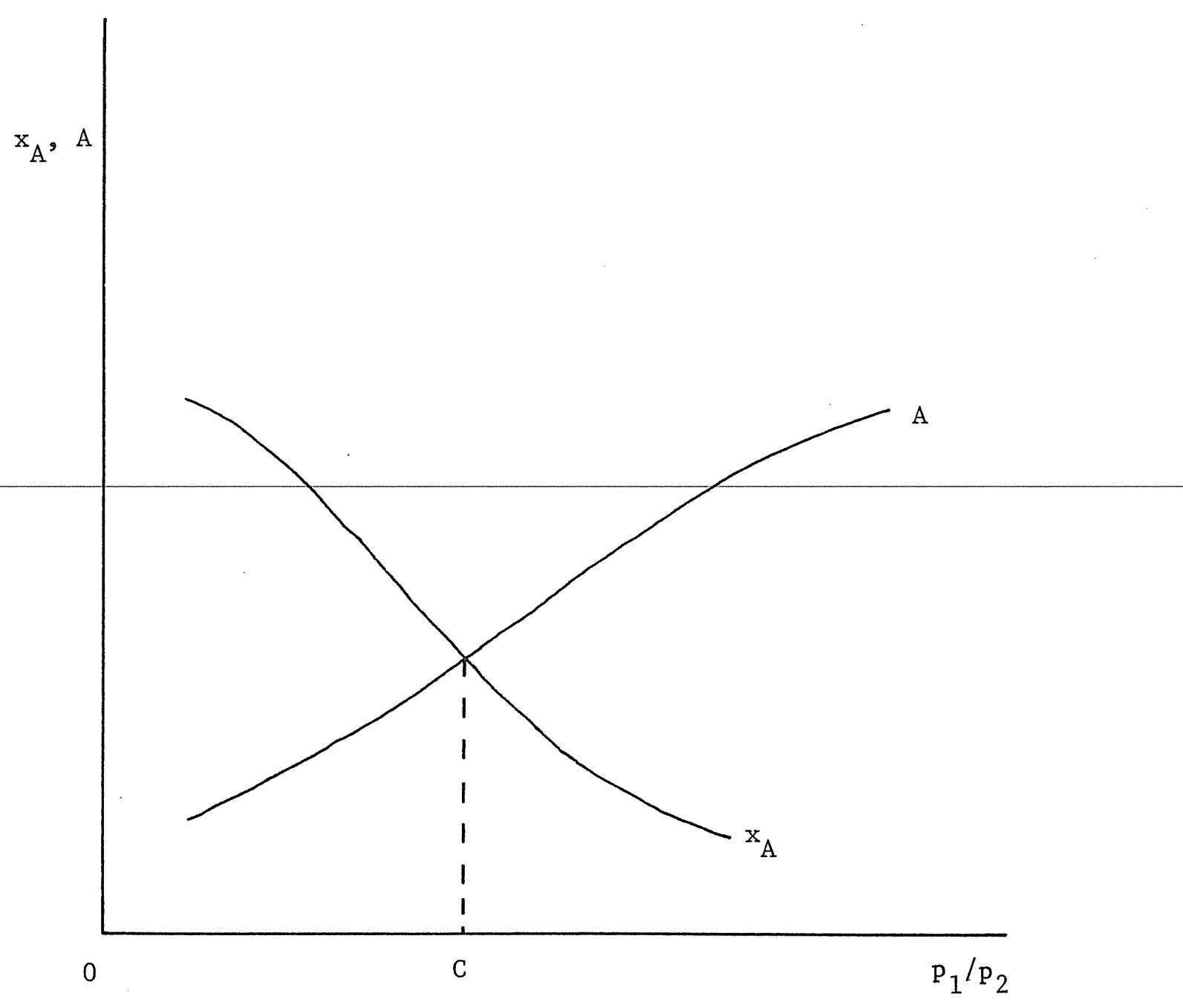

Figure 5 
For some value of the $\mathrm{p}_{1} / \mathrm{p}_{2}$ ratio, production and derived demand for middle products would be precisely balanced (Point $\underline{\mathrm{C}}$ in Figure 5) and trade would vanish. For higher values of $p_{1} / p_{2}$ the community would rely on the rest of the world to supply its thirst for middle-product $A$ as more $x_{1}$ is produced. For lower values of $\mathrm{p}_{1} / \mathrm{p}_{2}$, the community exports $A$. 
II. Tariffs

In analyzing the impact of a tariff in this model of trade in middle products we throughout make two simplifying assumptions, both standard in more traditional models: (i) the tariff-levying home country is small in world markets in the sense that its actions do not disturb world prices of middle products $\underline{A}$ and $\underline{B}$; (ii) initially free trade prevails. The upshot of these two assumptions is that for small tariffs we can ignore any change in aggregate real income at home. (In the following section we analyze a different but related issue - the effect of a change in world terms of trade, which has a direct impact on real incomes.)

Although aggregate welfare is not disturbed by the tariff, the distribution of real income is vitally affected by protection. However, with all final commodities being non-traded, consumer preference patterns must be considered in tracing through the impact of protection on factoral incomes and real outputs. In particular we emphasize two extreme types of demand response:

(i) the case in which the two non-tradeables are perfect substitutes for each other in consumer taste patterns, and (ii) the case in which price changes invoke absolutely no substitution response on the part of consumers. As we demonstrate, in case ( $i$ ) income distribution follows a Heckscher-Ohlin pattern, whereas in case (ii) the type of results familiar from specific-factor models emerges. Although each case is "extreme", the solution for wages, rentals and outputs in the general case in which demand is somewhat responsive to relative prices is literally a positive weighted average of the two extremes. 5

5) For an exposition of the usefulness in trade theory of these two extreme assumptions about tastes see Jones, [4]. 


\section{A. Constant Relative Price of Non-tradeables}

This is the case in which indifference curves for the two sectors of the Output Tier are downward sloping straight lines. Suppose the country imports middle product A and protects this sector with a tariff. As we shall see, this serves to twist the transformation schedule in Figure 2 so that at the original relative prices less of commodity 1 and more of commodity 2 are produced; the tariff has hit the industry which uses protected middle-product, A. The impact on factor incomes is strong and depends only upon factor-intensity rankings in the Output Tier. This is perhaps surprising, since it implies that technology and factor intensity ranking for the industry being protected count for little in determining the wage rate. Although physical intensity rankings are inappropriate in the specific-factor structure of the Input Tier, it is possible to make intersectoral comparisons of labor's distributive share. Suppose that $\theta_{\text {LA }}$ is greater than labor's share in any of the other three sectors. Nonetheless as $\mathrm{p}_{\mathrm{A}}$ rises with protection the real wage will unambiguously fall if the output sector in which $A$ is used as input (sector 1 in the Output Tier) is labor-intensive relative to the other sector (2) in the Output Tier. Factor proportions are crucial in explaining income distribution. But it is the intensity ranking solely in the Output Tier that matters.

These remarks find formal justification when (11) and (12), the competitive profit conditions in the Output Tier, are interpreted as (14) and (15) for the case in which $p_{B}$ is kept constant at its free trade world-determined level, $\mathrm{p}_{\mathrm{A}}$ is raised by the amount of the tariff, and with indifference curves linear the relative change in $p_{1}$ must be matched by the change in $p_{2}$. 
Let $\hat{\mathrm{p}}_{1}=\hat{\mathrm{p}}_{2}=\hat{\mathrm{p}}_{\mathrm{o}}$ :

(14) $\theta_{\mathrm{L} 1} \hat{\mathrm{w}}+\theta_{\mathrm{A} 1} \hat{\mathrm{p}}_{\mathrm{A}}=\hat{\mathrm{p}}_{\mathrm{O}}$

(15) $\theta_{\mathrm{L} 2} \hat{\mathrm{w}} \quad=\hat{\mathrm{p}}_{\mathrm{O}}$

Subtraction reveals that

(16) $\hat{\mathrm{w}}=-\frac{\theta}{|\theta|} \hat{\mathrm{p}}_{\mathrm{A}}$

where $|\theta|$, equal to the fraction $\left(\theta_{\mathrm{L} 1}{ }^{-\theta} \mathrm{L} 2\right)$, is positive if and only if $x_{1}$ is labor-intensive relative to $x_{2}$. Suppose it is. Then an increase in the domestic price of middle product $\underline{A}$ serves-as-a-reduetion in the effective price of industry 1 . As the theory of effective protection has shown for HeckscherOhlin-type models, such a price change serves to reduce the wage rate if labor is the intensively used factor in that sector. Note that the Output Tier has in general a specific-factors type of structure. In the preceding section this reduced to a Heckscher-Ohlin-type model because the relative price of middle products was held constant. Here $\mathrm{p}_{\mathrm{A}}$ rises relative to $\mathrm{p}_{\mathrm{B}}$, but the extreme assumption of linear indifference curves serves to keep the $\mathrm{p}_{1} / \mathrm{p}_{2}$ price ratio constant, thus once again allowing the strong income-distribution properties of simple HeckscherOhlin models.

The reduction in the wage rate must be accompanied by a flow of labor from the Output Tier to the Input Tier. If no labor were to shift between tiers, equation (2) reveals that the rise in $\mathrm{P}_{\mathrm{A}}$ would be passed on in a partial increase in the wage rate. But wages are determined in the Output Tier (given the rise in $\mathrm{p}_{A}$ ), and $\mathrm{L}_{I}$ becomes endogenous. With a substitution 
for the wage rate change, the solution for $\hat{\mathrm{L}}_{\mathrm{I}}$ from (2) is:

$$
\hat{\mathrm{L}}_{I}=\gamma_{I}\left[{ }_{\mathrm{A}}+\frac{{ }_{\mathrm{A} 1}}{|\theta|}\right] \hat{\mathrm{p}}_{\mathrm{A}}
$$

If the industry using $\mathrm{A}$ is labor-intensive, as we have been assuming, the wage rate must fall and sufficient labor must flow back to the Input Tier to drive the value of labor's marginal product down, even though a price rise $\left(\mathrm{p}_{\mathrm{A}}\right)$ has taken place in the Input Tier. The required labor reallocation is larger the greater the average elasticity of demand for labor in the Input Tier $\left(\gamma_{\mathrm{I}}\right)$.

The following ehain of inequali-ties-shows that when $\mathrm{p}_{\bar{A}}$ ri-ses and the relative price of non-traded outputs is kept constant by infinitely elastic demand, labor is

$$
\hat{\mathrm{r}}_{\mathrm{A}}>\hat{\mathrm{p}}_{\mathrm{A}}>\hat{\mathrm{p}}_{\mathrm{B}}(=0)>\hat{\mathrm{p}}_{\mathrm{O}}\left(=\hat{\mathrm{p}}_{1}=\hat{\mathrm{p}}_{2}\right)>\hat{\mathrm{w}}
$$

unambiguously harmed and the specific factors in the Input Tier become the net gainers. (The return to the factor used specifically to produce middle product $\underline{B}$ must at least rise, but may not rise by more than $\mathrm{p}_{\mathrm{A}}$.) Note also the general deflationary impact of the tariff-induced rise in the price of middle-product $\underline{A}$. This is brought about by the required drop in the wage rate, which pulls costs of non-tradeables down.

Should the alternative factor-intensity ranking have prevailed in the Output Tier (with $x_{2}$ being labor-intensive), the "effective" price of the labor-intensive commodity would rise as $\mathrm{p}_{\mathrm{A}}$ rises, the wage rate would rise even relative to $\mathrm{p}_{\mathrm{A}}$ and, of course, relative to final commodity prices $\left(p_{0}\right)$ which are nonetheless raised to some extent. Indeed a ten percent rise in the duty on A would 
cause final goods prices to rise by more than ten percent, since the wage rate would increase by more than ten percent.

Although the impact of a protectionist policy on wages depends upon factor intensities in the Output Tier, the effect on outputs (at a constant final goods relative price) is unambiguous: output in the industry using the protected input must fall while the other final product expands. Figure 6 illustrates the argument. The economy initially produces at point $\underline{\mathrm{C}}$. The dashed line through $\underline{\mathrm{C}}$ reflects the given relative price ratio, $\mathrm{p}_{1} / \mathrm{p}_{2}$, and for small tariffs outputs remain on this line since aggregate real income is undisturbed. If $x_{1}$ is laborintensive, the labor constraint line must be steeper than this line. ${ }^{6}$ And a rise in $\mathrm{p}_{\mathrm{A}}$ causes the labor constraint line to shift in towards the origin both because labor is driven towards the Input Tier and because the fall in wages encourages a more intensive use of labor throughout the Output Tier. The postprotection output is at a point such as $\underline{D}$. If $x_{2}$ had been laborintensive, the labor constraint line would have been flatter than the dashed line but it would have shifted outwards from the origin as real wages rise and labor is reallocated to the Output Tier. Again point $\underline{D}$ represents the new output combination. In the Input Tier the rise in $\mathrm{p}_{\mathrm{A}}$ and the inflow of labor from the Output Tier both conspire to raise output and employment in the protected A industry. Furthermore, the demand for middle product $A$ is reduced both because $x_{1}$ final output falls and because the rise in $\mathrm{p}_{\mathrm{A}}$ (and fall in $\mathrm{w}$ ) cause less intensive use of A per unit of $x_{1}$ output. That is, Figure 5 's $x_{A}$ schedule shifts upwards, the A-schedule downwards, and the tariff unambiguously reduces imports.

6) That is, $\mathrm{p}_{1} / \mathrm{p}_{2}$ reflects an average of 1 abor costs (which bite more severely on the labor-intensive sector) and middle product costs. 
$I I-5 a$

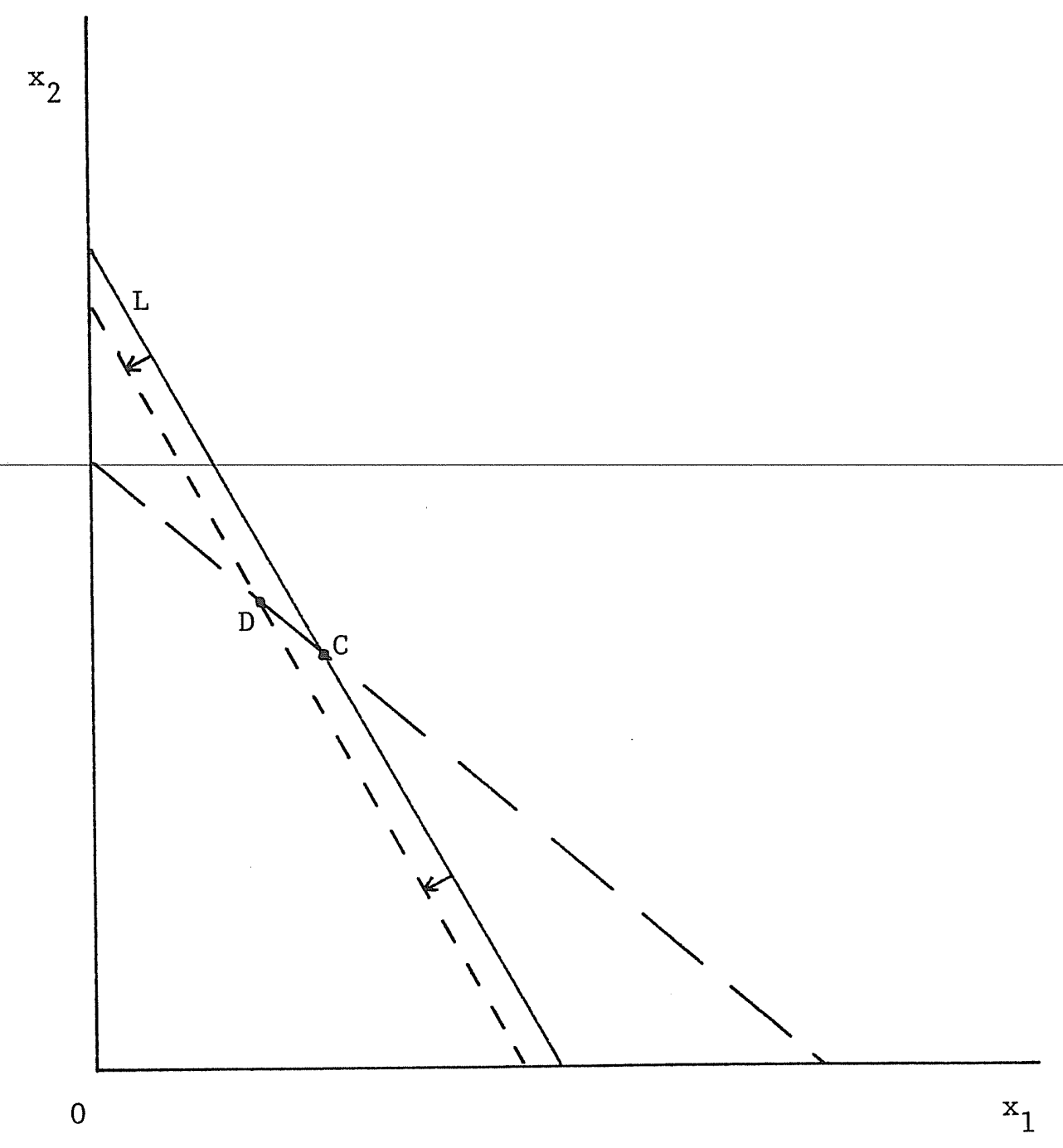

Figure 6 


\section{B. Zero Flexibility in Demand}

The other extreme form of demand function - right angled indifference curves that do not allow substitution between $x_{1}$ and $\mathrm{x}_{2}$ for consumers - requires output levels to remain unchanged. Consumers resist the preceding section's demonstrated fall in $x_{1}$ output at constant relative prices, and $\mathrm{p}_{1} / \mathrm{p}_{2}$ will be bid up. The resultant impact of protection on real wages will be less marked than without this price movement.

To analyze the allocation of labor between tiers, assume, initially, that it is frozen. By (2) the rise in $\mathrm{p}_{\mathrm{A}}$ would drive up the wage rate in the Input Tier by the fraction, $\beta_{A}$, of the rise in $\mathrm{P}_{\mathrm{A}}$. In the Output Tier both individual sectors' output can remain constant only if the labor constraint line does not shift. With reference to equation (5), if $\mathrm{L}_{\mathrm{o}}$ is temporarily frozen, the wage rate must respond in order to keep the average intensity with which labor is used from changing. That is, the weighted average, $\left\{\lambda_{L 1} \hat{a}_{L 1}+\lambda_{L 2} \hat{a}_{L 2}\right\}$, must be zero. This cannot be accomplished by setting each labor coefficient constant, since the price of only one middle product has changed and both sectors draw from a common labor pool. The rise in $\mathrm{p}_{\mathrm{A}}$ would, at the initial wage, cause the first industry to use labor more intensively. A rise in the wage would help mitigate this effect in the first industry as well as cause the second industry to adopt less labor-intensive techniques. The rise in $a_{L 1}$ will just match the fall in $a_{L 2}$ for some rise in w which represents a fraction - call it $\rho_{A}$ - of the rise in $A^{\prime}$ 's price. Since

$$
\hat{a}_{L 1}=-\theta_{A 1} \sigma_{1}\left(\hat{w}-\hat{p}_{A}\right)
$$

and $\hat{a}_{\mathrm{L} 2}=-\theta_{\mathrm{B} 2} \sigma_{2} \hat{\mathrm{w}}$,

the value for $\rho_{\mathrm{A}}$ is 


$$
\rho_{\mathrm{A}} \equiv \frac{\lambda_{\mathrm{L} 1}{ }^{\theta_{\mathrm{A} 1} \sigma_{1}}}{\lambda_{\mathrm{L} 1}{ }^{\theta}{ }_{\mathrm{A} 1} \sigma_{1}+\lambda_{\mathrm{L} 2}{ }_{\mathrm{B} 2} \sigma_{2}}=\frac{\lambda_{\mathrm{L} 1}{ }^{\theta_{\mathrm{A} 1} \sigma_{1}}}{\delta_{\mathrm{L}}}
$$

There is no reason why $\rho_{A}$, which depends upon technology in the Output Tier, should match $\beta_{\mathrm{A}}$, which depends upon technology in the Input Tier. If $\beta_{A}$ exceeds $\rho_{A}$, labor will be attracted to the Input Tier and this will drive the wage below $\beta_{A} \hat{p}_{A}$. If $\beta_{A}$ falls short of $\rho_{A}$, labor flows out of the Input Tier, causing labor's marginal product there to rise. Equilibrium in the labor market requires a common wage rate, and protection of the A-industry will raise $\underline{w}$ by an amount between $\beta_{A} \hat{p}_{A}$ and $\rho_{A} \hat{p}_{A}$. Formally, ${ }^{6 a}$

(17) $\hat{\mathrm{w}}=\zeta \hat{\mathrm{p}}_{\mathrm{A}} \quad$ where $\zeta \equiv\left\{\alpha_{I} \beta_{A}+\alpha_{0} \rho_{A}\right\}, \quad \alpha_{I}+\alpha_{0}=1$

and $\quad \alpha_{I} \equiv \frac{\lambda_{L I} \gamma_{I}}{\lambda_{L I} \gamma_{I}+\lambda_{L O} \delta_{L}}$

This is derived by solving (5) for the value of $\hat{\mathrm{L}}_{\mathrm{o}}$ that sets the right-hand side of (5) equal to zero and, with the link between $\hat{\mathrm{L}}_{\mathrm{O}}$ and $\hat{\mathrm{L}}_{I}$ defined by full employment, solving (2) for $\hat{\mathrm{W}}$. If outputs are kept rigid, a rise in the duty on imports of $\underline{A}$ will cause a partial rise in the wage rate, even taking into account possible labor reallocation between tiers.

The impact of protection on income distribution for this special case is summarized in the following chain of inequalities:

$$
\hat{\mathrm{r}}_{\mathrm{A}}>\hat{\mathrm{p}}_{\mathrm{A}}>\hat{\mathrm{p}}_{1}>\hat{\mathrm{w}}>\hat{\mathrm{p}}_{2}>\hat{\mathrm{p}}_{\mathrm{B}}(=0)>\hat{\mathrm{r}}_{\mathrm{B}} \text {. }
$$

The wage rate change is trapped between $\hat{\mathrm{p}}_{\mathrm{A}}$ and $\hat{\mathrm{p}}_{\mathrm{B}}$ (equal to zero), as in the specific factor model but with slightly different weights since some labor reallocation between tiers takes place. Both

6a) An increase in the wage rate shifts the $\mathrm{L}_{0}$ constraint outwards for two reasons: more labor is attracted from the Input Tier, and less labor is required per unit output in the Output Tier. $\alpha_{I}$ reflects the relative importance of the labor released from the Input Tier. 
final goods prices rise - more so relatively in the industry employing the dutiable input. Just as labor is relatively unaffected by protection, the specific factors employed in the Input Tier find their returns either greatly raised (in the protected sector A) or unambiguously reduced (in the other sector in the Input Tier).

Outputs change in the Input Tier in much the same fashion as in the earlier case. The sector producing protected middle product $\underline{A}$ must expand. The rise in $\mathrm{p}_{\mathrm{A}}$ would increase $\mathrm{x}_{\mathrm{A}}$ along Figure 1's transformation schedule if the inter-tier labor allocation were fixed. However, labor may flow out of the Input Tier and, at constant prices, this would tend to reduce $\mathrm{x}_{\mathrm{A}}$. The key relationship follows if the quantity of specific factor $V_{A}$ is assumed constant, for then $\mathrm{x}_{\mathrm{A}}$ can expand if and only if $\mathrm{V}_{\mathrm{A}}$ is used less intensively, as it must be used since in any case the real wage has fallen in the $\mathrm{x}_{\mathrm{A}}$ sector. In the Output Tier the derived demand for $\underline{A}$ has fallen since $x_{1}$ output is constant but the fall in the input price ratio, $\mathrm{w} / \mathrm{p}_{\mathrm{A}}$, causes $\mathrm{A}$ to be used less intensive1y. In Figure 5, although $\mathrm{p}_{1} / \mathrm{p}_{2}$ now rises, the upward shift in the $x_{A}$ curve and downward shift in the A-schedule must dominate so that imports of $A$ are cut by the protective action.

\section{Protection in the General Case}

If we assume demand for the two final non-tradeables is captured by a set of smoothly bowed-in homothetic indifference curves, compositional changes in the Output Tier must satisfy (18):

$$
\left(\hat{x}_{1}-\hat{x}_{2}\right)=-\sigma_{D}\left(\hat{p}_{1}-\hat{p}_{2}\right)
$$

$\sigma_{D}$ is the elasticity of substitution in demand. The two preceding extreme cases had $\sigma_{D}=\infty$ and $\sigma_{D}=0$ respectively. 


\section{II -9}

In the discussion of output changes in the preceding section we examined the shifts in the labor constraint, equation (5), and in the constraint from the supply of middle products, equation (6), in a symmetric fashion. An alternative route, which proves to be more simple in all the applications we consider, is to make use of the labor constraint, (5), in conjunction with a relationship showing how the real value of aggregate outputs changes in the Output Tier. For example, for the preceding section's output movements along the transformation schedule,

(19) $\theta_{1} \hat{x}_{1}+\theta_{2} \hat{x}_{2}=0$,

a reflection of the tangency of the price line to the schedule.

${ }_{j}$ refers to the fraction of national income represented by the value of sector j's output. Relationship (19) also holds in the present case of a small tariff from a position of initial free trade (and no change in the terms of trade). The tariff will cause the transformation schedule to shift - but in a "sideways" fashion along the pre-existing tangent line. That is, the real yalue of aggregate output or real income does not change. In later applications, e.g. when the terms of trade are altered, real income will be affected.

The shift in the labor constraint, captured by the righthand side of equation (5), combines a change in labor's allocation between tiers, $\hat{\mathrm{L}}_{\mathrm{O}}$, and changes in the average intensity with which labor is used in the two non-traded sectors of the Output Tier. Each term is affected both by any change in wages and, in the present case, by a tariff-inspired change in $\mathrm{p}_{\mathrm{A}}$. For example, $\hat{\mathrm{L}}_{\mathrm{o}}$ is linked by (9) to $\hat{\mathrm{L}}_{I}$, and $\hat{\mathrm{L}}_{I}$ by (2) both to $\hat{\mathrm{w}}$ and $\hat{\mathrm{p}}_{\mathrm{A}}$. Thus: 


$$
\hat{\mathrm{L}}_{\mathrm{O}}=\frac{\lambda_{\mathrm{LI}} \gamma_{I}}{\lambda_{L O}}\left\{\hat{\mathrm{w}}-\beta_{\mathrm{A}} \hat{\mathrm{p}}_{\mathrm{A}}\right\}
$$

If wages are to rise by more than $\beta_{A} \hat{p}_{A}$, labor's marginal productivity in the Input Tier must be bid up a departure of labor to the Output Tier. The change in labor intensities is shown by:

$$
-\left\{\lambda_{L 1} \hat{a}_{L 1}+\lambda_{L 2} \hat{a}_{L 2}\right\}=\delta_{L}\left(\hat{w}-\rho_{A} \hat{p}_{A}\right) \text {. }
$$

Combining these terms yields (20) as the rewritten form of (5):

$$
\begin{aligned}
\lambda_{L 1} \hat{x}_{1}+\lambda_{L 2} \hat{x}_{2} & =\omega\left\{\hat{w}-\zeta \hat{p}_{A}\right\}, \\
\text { where } \omega & \equiv \frac{\lambda_{L I} \gamma_{I}}{\lambda_{L o}}+\delta_{\bar{L}} .
\end{aligned}
$$

The term $\omega$ has a ready interpretation. Suppose the wage rate rises by $1 \%$ and prices of middle products are constant. The labor constraint line on outputs in the Output Tier will then shift outwards by $\omega \%$, reflecting both the ability to draw labor from the Input Tier as wages rise, and the ease with which technology in the Output Tier adapts to less labor-intensive techniques.

Now subtract equation (19) from (20) to obtain the change in the ratio of outputs produced:

$$
\left(\hat{x}_{1}-\hat{x}_{2}\right)=\frac{\omega}{\left(\lambda_{L 1}-\theta_{1}\right)}\left[\hat{w}-\zeta \hat{p}_{A}\right]
$$

The denominator of this expression has a positive sign if and only if $x_{1}$ is labor-intensive. Indeed, it can be shown to equal $\theta_{T}|\lambda|$, where $\theta_{\mathrm{T}}$ is the fraction of the national income represented by the value of output of tradeables in the Input Tier. With this substitution, the change in the ratio of outputs produced is: ${ }^{7}$

7) Compare (21) with equation (10). The coefficients of $\hat{\mathrm{w}}$ must be the same. That is, $\omega$ can also be expressed by $\theta_{\mathrm{T}}$ times $\left\{\delta_{L}+\delta_{T}+\frac{\theta_{L I}}{\theta_{L o}} \gamma_{I}\right\}$ 
(21)

$$
\left(\hat{\mathrm{x}}_{1}-\hat{\mathrm{x}}_{2}\right)=\frac{\omega}{\theta_{\mathrm{T}}|\lambda|}\left[\hat{\mathrm{w}}-\zeta \hat{\mathrm{p}}_{\mathrm{A}}\right]
$$

Fu11 equilibrium requires that markets for non-tradeables clear - the output changes shown by (21) must match the demand changes shown by (18). But first rewrite (18) in terms of factor prices by subtracting (12) from (11) (with constant $\mathrm{p}_{\mathrm{B}}$ ) to obtain:

$$
\left(\hat{\mathrm{x}}_{1}-\hat{\mathrm{x}}_{2}\right)=-\sigma_{D}\left\{|\theta| \hat{\mathrm{w}}+\theta_{\mathrm{A} 1} \hat{\mathrm{p}}_{\mathrm{A}}\right\}
$$

Therefore the market-clearing change in the wage rate, relative to the tariff, is shown by (22) to be a weighted average of the two extreme cases in which $\sigma_{D}=0$ and $\sigma_{D}=\infty$ :

$$
\frac{\hat{W}}{\hat{p}_{A}}=\kappa_{0} \zeta+\kappa_{\infty}\left\{-\frac{{ }^{A} 1}{|\theta|}\right\}
$$

$$
\text { where } \kappa_{0} \equiv \frac{\omega}{\omega+\theta_{\mathrm{T}}|\lambda||\theta| \sigma_{\mathrm{D}}} ; \quad \kappa_{0}+\kappa_{\infty} \equiv 1 \text {. }
$$

Other things equal, the greater the degree of substitutability on the demand side, the more the wage response resembles that in a Heckscher-Ohlin model in which the tariff provides effective protection to the industry not relying upon imports and in which income distribution depends crucially upon factor intensities. 7a

7a) Following up on the preceding footnote, the weight $\kappa_{0}$ can be expressed as

$$
\frac{\left\{\delta_{L}+\delta_{T}+\frac{{ }^{\theta_{L I}}}{\theta_{L o}} \gamma_{I}\right\}}{\left\{\delta_{L}+\delta_{T}+\frac{{ }_{L I}}{{ }_{\text {}}} \gamma_{I}\right\}+|\lambda||\theta| \sigma_{D}}
$$

Furthermore, letting $\sigma_{S}$ denote the elasticity of substitution along the Output Tier's transformation schedule - shown by the bracketed term in equation (13) - this expression for the weight $k_{0}$ reduces to $\frac{\sigma_{S}}{\sigma_{S}+\sigma_{D}}$. The importance of the relative size of $\sigma_{S}$ and $\sigma_{D}$ for issues in growth theory and taxation was pointed out in Jones, [3], Chapter 4 . 
III. The Terms of Trade

The preceding analysis of tariffs lays the basic groundwork for investigating the impact on the economy of a change in the terms of trade. The key distinction that must be made concerns the income effects that are linked to the extent and direction of changes in world prices of middle products and the volume and direction of trade.

These income effects are reflected in outward or inward shifts of the transformation schedule for the Output Tier. More precisely, Figure 7 illustrates how a rise in $\mathrm{p}_{\mathrm{A}}$ serves to rotate the transformation schedule clockwise around point $C$, which represents the autarky point of production. For relatively high values of $\mathrm{p}_{1} / \mathrm{p}_{2}$, the economy imports middle product $\underline{\mathrm{A}}$ and must be hurt by a rise in $\underline{A}^{\prime}$ 's price, whereas for low values it gains as an exporter of $\underline{\text { A. }}$

The precise relationship between national welfare and the terms of trade is shown in (23):

$$
\theta_{1} \hat{\mathrm{x}}_{1}+\theta_{2} \hat{\mathrm{x}}_{2}=\theta_{\mathrm{x}} \hat{\mathrm{p}}_{\mathrm{A}} \quad \text { where } \theta_{\mathrm{x}} \equiv \frac{\mathrm{p}_{\mathrm{A}}\left(\mathrm{x}_{\mathrm{A}}-\mathrm{A}\right)}{\mathrm{Y}}
$$

$\theta_{x}$ is the share of exports of $A$ in the national income - a fraction that is negative if $\underline{A}$ is imported. 8 This relationship substitutes for equation (19), but the procedure whereby wages are determined is similar to the tariff case. In particular, subtraction of (23) from (20) now yields

8) The formal argument is brief: in the Output Tier the value of output, $\mathrm{p}_{1} \mathrm{x}_{1}+\mathrm{p}_{2} \mathrm{x}_{2}$, equals $\mathrm{p}_{\mathrm{A}} \mathrm{A}+\mathrm{p}_{\mathrm{B}} \mathrm{B}+\mathrm{wL} \mathrm{L}_{\mathrm{O}}$. Since the financial components of change cancel due to the competitive profit conditions (i.e. since $x_{1} d p_{1}+x_{2} d p_{2}=A d p_{A}+B d p_{B}+L_{O} d w$ ), $\left\{\mathrm{p}_{1} \mathrm{dx} \mathrm{x}_{1}+\mathrm{p}_{2} \mathrm{dx}_{2}\right\}$ must equal $\left\{\mathrm{p}_{\mathrm{A}} \mathrm{dA}+\mathrm{p}_{\mathrm{B}} \mathrm{dB}+\mathrm{wdL}_{\mathrm{o}}\right\}$. But since balanced trade requires $\left\{p_{A} A+p_{B} B\right\}$ to equal $\left\{p_{A} x_{A}+p_{B} x_{B}\right\}$, we have $\left\{p_{A} d A+p_{B} d B\right\}$ equal to $\left\{p_{A} d x_{A}+p_{B} d x_{B}\right\}+\left(x_{p}-A\right) d p_{A}$ when $p_{B}$ is kept constant. And $\left\{\mathrm{p}_{\mathrm{A}} \mathrm{dx}_{\mathrm{A}}+\mathrm{p}_{\mathrm{B}} \mathrm{dx_{ \textrm {B } }}\right\}$ equals $\mathrm{wdL}_{\mathrm{I}}$. Therefore $\left\{\mathrm{p}_{1} \mathrm{dx} \mathrm{x}_{1}+\mathrm{p}_{2} \mathrm{dx}_{2}\right\}=\left(\mathrm{x}_{\mathrm{A}}-\mathrm{A}\right) \mathrm{dp_{A }}$, which is equivalent to equation (23). 


$$
\text { III - } 1 a
$$

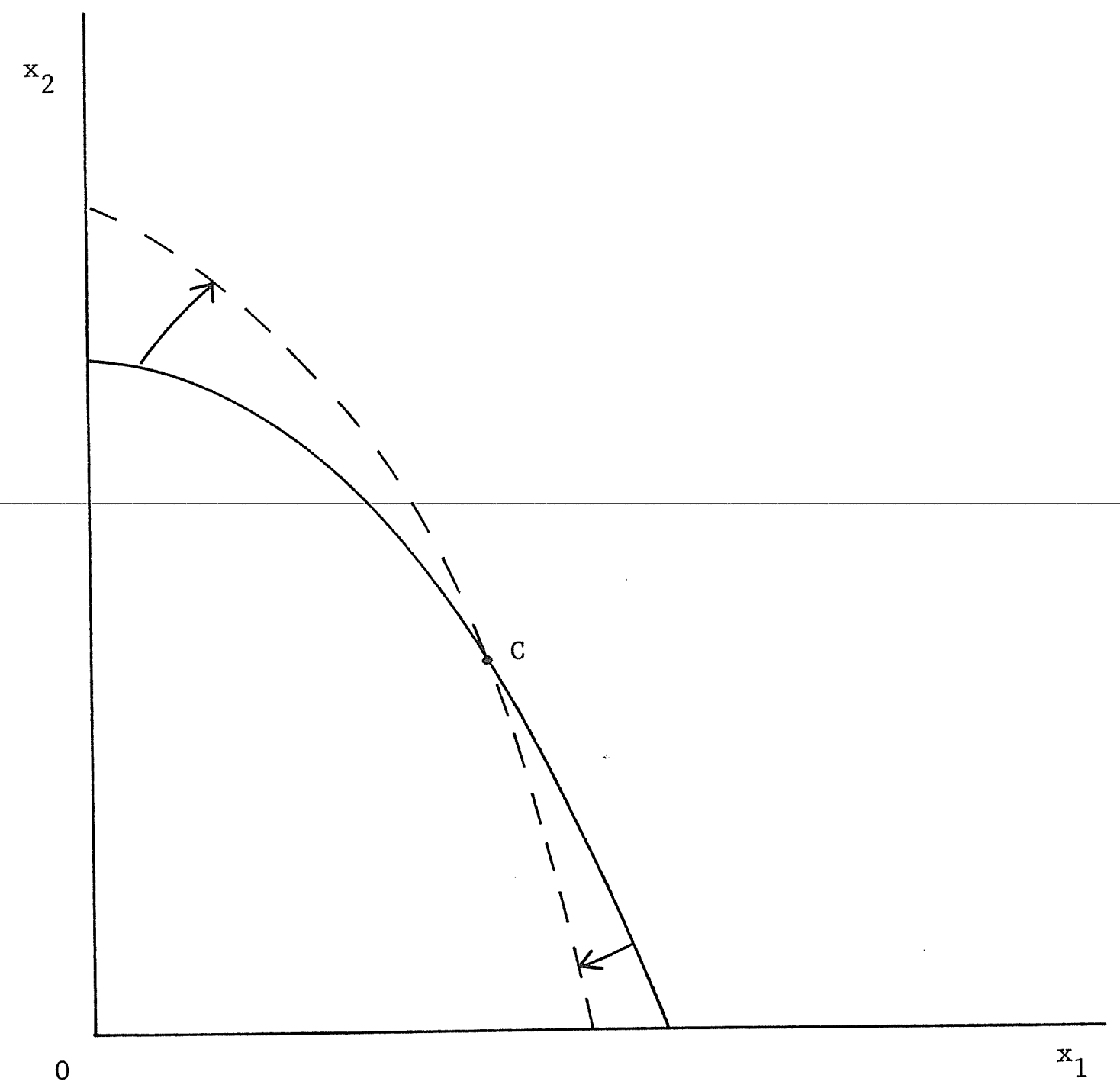

Figure 7 
(24) $\left(\hat{\mathrm{x}}_{1}-\hat{\mathrm{x}}_{2}\right)=\frac{\omega}{\theta_{\mathrm{T}}|\lambda|}\left\{\hat{\mathrm{w}}-\left(\zeta+\frac{\theta_{\mathrm{x}}}{\omega}\right) \hat{\mathrm{p}}_{\mathrm{A}}\right\}$.

The change in the ratio of final goods demanded is shown by (18), with $\left(\hat{\mathrm{p}}_{1}-\hat{\mathrm{p}}_{2}\right)$ once again given by $\left\{|\theta| \hat{\mathrm{w}}+{ }_{\mathrm{A} 1} \hat{\mathrm{p}}_{\mathrm{A}}\right\}$. Equating supply and demand yields (25) as the solution for the wage rate change for the case in which the world price of middle product $\underline{A}$ rises:

$$
\frac{\hat{w}}{\hat{p}_{A}}=\kappa_{0}\left\{\zeta+\frac{\theta}{\omega}\right\}+\kappa_{\infty}\left\{-\frac{\theta A}{|\theta|}\right\}
$$

This result should be compared with the earlier effect of a

tariff-induced rise in the price of $\underline{A}$ on wages given by (22).

A change in the terms of trade affects national welfare. But

it is labor that gains or loses depending on the pattern of trade. For any given values of demand elasticities (short of infinite) compare two situations - one in which $\underline{A}$ is exported and the other in which $\mathrm{A}$ is imported. In the former case the wage rate rises by more than in the latter (if it goes up at a11). And just the reverse is true for other classes of income recipients. Consider the competitive profit conditions in the Input Tier,

$$
\begin{aligned}
& \theta_{L A} \hat{\mathrm{w}}+\theta_{V A} \hat{\mathrm{r}}_{A}=\hat{\mathrm{p}}_{A} \\
& \theta_{L B} \hat{\mathrm{w}}+\theta_{V B} \hat{\mathrm{r}}_{B}=0,
\end{aligned}
$$

for a given rise in $\mathrm{p}_{\mathrm{A}}$. As (25) reveals, if $\mathrm{p}_{\mathrm{A}}$ rises and demand elasticities are not too high, the wage rate rises, but only by a fraction of the rise in $\mathrm{p}_{\mathrm{A}}$. Therefore the rental return to the factor specific to the $x_{A}$ sector rises by a magnified amount, and the return to the factor tied to the other traded sector (B) falls. But the wage rise is greater the greater the net exports of $\underline{A}$, and 
this serves directly to lower the returns to specific factors below what they would otherwise earn. In this sense labor's interests are identified with that of the economy as a whole, whereas those of specific factors are not.

Consider, now, the relevance of demand elasticities. As (25) or, indeed, (22) shows, the higher is the value for $\sigma_{D}$ the greater the weight that is associated with the "HeckscherOhlin" component of the wage change, $\left\{{ }^{-\theta} \mathrm{A} 1 /|\theta|\right\}$. That is, with high values of $\sigma_{\mathrm{D}}$ labor stands to gain or lose a magnified amount depending upon factor intensity rankings in the Output Tier. But more can be said. The higher the value of $\sigma_{\mathrm{D}}$ the less do national gains or losses associated with changes in the terms of trade affect wages. If $\sigma_{D}$ were infinite, the wage rate change would exactly correspond to equation (16) in which no national gains or losses accrued to the nation. By contrast, if demand is quite inelastic labor's net position is heavily dependent upon the pattern of trade.

The change in the real value of final outputs produced that is associated with a change in the terms of trade introduces an ambiguity about output changes in both tiers that is absent in the case of protection. To illustrate, suppose the economy is initially in full equilibrium at point $\underline{\mathrm{C}}$ in Figure 8 where the labor constraint line for the output tier intersects the flatter line drawn tangent to the transformation curve at $\underline{C}$. That is, assume $\mathrm{x}_{1}$ is labor-intensive. If $\mathrm{p}_{\mathrm{A}}$ rises on world markets, at what combination of outputs will the new, rotated, transformation schedule have the same slope as the intial one at $\underline{C}$ ? The labor constraint line shifts towards the origin. This shift is generally slight if elasticities of substitution throughout the economy are 


$$
\text { III - } 3 a
$$

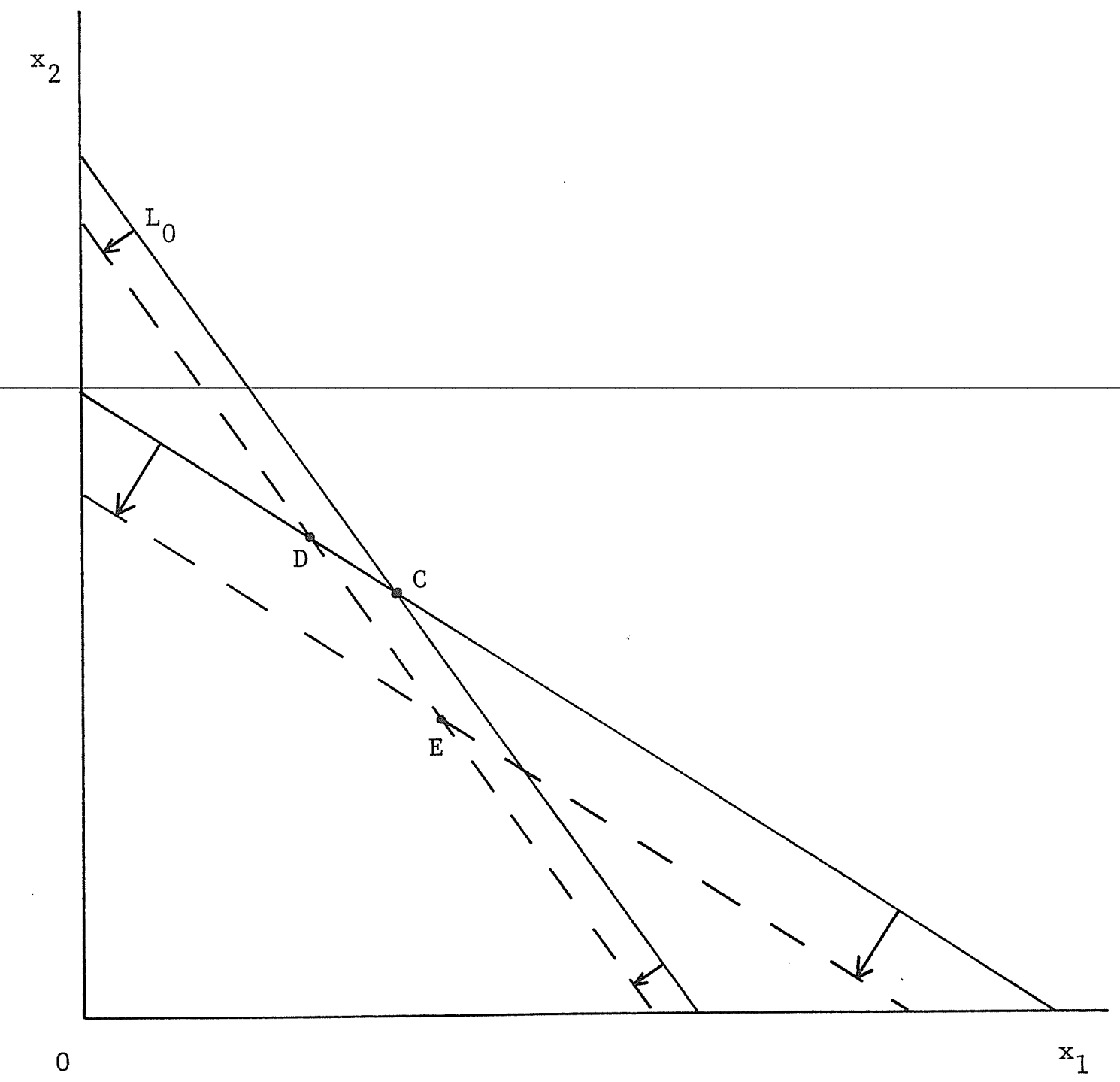

Figure 8 
1ow. If the rise in $\mathrm{p}_{\mathrm{A}}$ had left real incomes unchanged, output would have moved to point $\underline{D}$, such as in the tariff case. The rise in $\mathrm{p}_{\mathrm{A}}$ penalizes the A-using industry, $\mathrm{x}_{1}$, to the benefit of the other non-traded sector, $x_{2}$. If $A$ is exported, such a switch would be accentuated, with the new equilibrium point northwest of $\underline{D}$. However, if $\underline{A}$ is imported, and if imports are a large fraction of national income, the drop in the tangent line to the transformation schedule could lead to a new point, E, in which the $\mathrm{x}_{1} / \mathrm{x}_{2}$ ratio has expanded.

Anomalies are also possible in the Input Tier. Suppose the country exports middle product $\underline{A}$ and its terms of trade improve. The increase in real incomes must find reflection in an increase in the value (at initial prices) of final goods output which could cause labor to be reallocated towards the Output Tier. If the rise in $\mathrm{p}_{\mathrm{A}}$ causes relatively little expansion in $\mathrm{x}_{\mathrm{A}}$-production along a given transformation schedule (e.g. see Figure 1), because substitution possibilities there are narrow, the backward shift in the transformation schedule as labor is attracted to the Output Tier may result in a net loss of $\mathrm{x}_{\mathrm{A}}$ output. Alternatively put, if $\underline{A}$ is the export sector, a rise in $\mathrm{p}_{\mathrm{A}}$ could raise the wage rate even higher than the increase in $\mathrm{p}_{\mathrm{A}}$ (see equation (25)). This rise in 1 abor's real wage in the $\mathrm{x}_{\mathrm{A}}$ sector would cause output there to contract despite protection. 


$$
\text { IV }-1
$$

\section{Technical Progress}

The exogenous changes considered in the last three sections concerned relative price changes within a tier. In this and the next section we consider the impact of changes in the economy that affect primarily the relationship between the Input Tier and the Output Tier. In this section we analyze the case of uniform Hicksian technical progress that is limited, in the first instance, to the Input Tier and, in the second, to the Output Tier.

Suppose in the Input Tier that coefficients both for labor and for specific factors are reduced uniformly (for given factor price ratios) by the relative amount, $\pi$. As was the case with changes in a tariff or the terms of trade, the effect of such a change on income distribution and outputs depends in some degree on the nature of consumer tastes for final products. Again, it proves useful to consider the two extremes of infinite substitutability and zero substitutability. In the former case a strong result is immediate: labor captures none of the benefits of technical progress. This conclusion follows from the competitive profit conditions in the Output Tier, (11) and (12), when middle-product prices are kept constant. With labor-intensities assumed to differ, the only solution when $\hat{\mathrm{p}}_{1}=\hat{\mathrm{p}}_{2}$ (since indifference curves are linear) is for $\hat{\mathrm{W}}$ to equal zero and neither non-traded good price to change. In other words, labor's real income is unaffected and all the gains from technical progress accrue to the specific factors in the Input Tier.

To pursue the details in the Input Tier, reconsider the meaning of the elasticity of labor's marginal product curve, $\gamma_{j}$, $(j=A, B)$. Without technical progress $\gamma_{A}$, for example, would equal $-\left(\hat{a}_{L A}-\hat{a}_{V A}\right) /\left(\hat{w}-\hat{p}_{A}\right)$, or, with middle-product prices held 
fixed, the change in the wage rate would equal $-\frac{1}{\gamma_{A}}\left(\hat{a}_{L A}-\hat{a}_{V A}\right)$. In the case of Hicksian neutral technical progress at rate $\pi$, the marginal product curve shifts upwards by $\pi$ so that even with factor proportions unchanged the real wage rises. Combining yields

$$
\hat{w}=\pi-\frac{1}{\gamma_{j}}\left(\hat{a}_{L j}-\hat{a}_{V j}\right), \quad j=A, B,
$$

for fixed prices of $\underline{A}$ and $\underline{B}$. Proceeding to solve for the wage rate change as in section I reveals that it depends upon the extent of technical progress, $\pi$, and the reallocation of labor between tiers. That is, equation (26) replaces (2) for $\hat{w}$ :

(26) $\hat{\mathrm{w}}=\pi-\frac{1}{\gamma_{I}} \hat{\mathrm{L}}_{\mathrm{I}}$

We have already established that if relative prices of nontraded goods in the Output Tier are prevented from changing by highly elastic consumer demand, their absolute levels cannot change and the wage rate must be constant. As (26) shows, this requires an absorption of labor into the Input Tier,

$$
\hat{\mathrm{L}}_{I}=\gamma_{I} \pi
$$

by an amount which depends upon the Input Tier's average derived elasticity of demand for labor.

The required output changes for non-tradeables are rather severe in this case. Figure 9 shows the initial output combination, $\underline{\mathrm{C}}$, in the Output Tier determined by the labor allocation, middle product prices, and technical coefficients consistent with initial full employment. Before any labor is reallocated, the T-constraint, given by the Input Tier's transformation schedule and world prices for traded middle products, shifts out because of the presumed uniform Hicksian technical progress throughout the Input Tier. 
$I V-2 a$

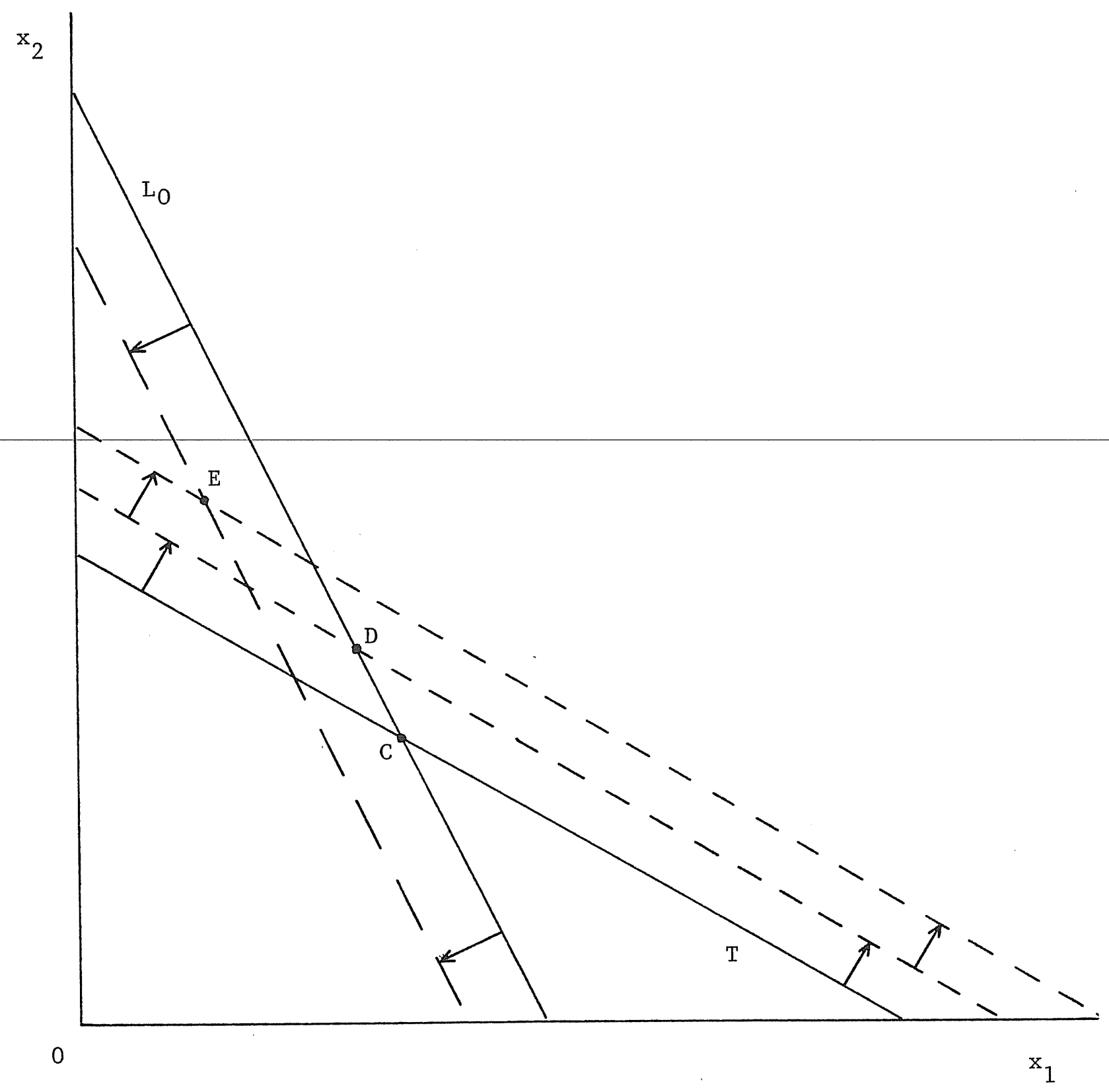

Figure 9 
This change by itself would cause outputs of $x_{1}$ and $x_{2}$ to shift from $\underline{C}$ to $\underline{D}$ and, in relative terms, $\hat{T}$ would equal $\pi$. But the wage rate tends to rise in the Input Tier unless labor is attracted from the Output Tier. The necessity of this labor reallocation to keep wages unchanged (at unchanged prices, $\mathrm{p}_{1}$ and $\mathrm{p}_{2}$ ) induces a further outward shift in the T-constraint and inward shift in the $\mathrm{L}_{\mathrm{o}}$ constraint, to the new intersection at $\underline{E}$.

The relationship between the $L_{o}$ and $T$ constraints in Figure 9 presupposes that commodity 1 is labor-intensive. The impact on the Output Tier's transformation schedule is to shift it outwards, but in the direction of T-intensive commodity 2. That is, technical

progress in the Input Tier biases final output production away from the 1abor-intensive commodity (as the Output Tier loses labor) and towards the commodity intensive in its use of traded middle products.

The extreme form of income distribution associated with this case - with labor gaining nothing and specific factors all - would be moderated if consumers resist such a drastic change in their consumption patterns. If the reduction in output of labor-intensive commodity 1 serves to drive up its relative price, labor begins to share in the gains from improved technology.

Consider now the extreme case in which indifference curves are right-angled and output proportions remain constant. If no labor reallocates, the wage rate in the Input Tier would rise by relative amount $\pi$, the degree of technical change. In the output Tier production of $x_{1}$ and $x_{2}$ expand in fixed proportions. The value of the real output rise before labor reallocates ${ }^{2}$ is

9) If labor reallocation is allowed, $p_{1} d x_{1}+p_{2} d x_{2}=d T+w d L_{o}$. But then $d T$ equals $\pi T+w \mathrm{dL}_{I}$. Since total labor supply, $\mathrm{L}_{0}+\mathrm{L}_{I}$, is constant, once again $\theta_{1} \hat{x}_{1}+\theta_{2} \hat{x}_{2}=\theta_{T} \pi$. 


$$
\text { IV }-4
$$

$$
p_{1} d x_{1}+p_{2} d x_{2}=d T
$$

or, equivalently in relative terms,

(27) $\theta_{1} \hat{x}_{1}+\theta_{2} \hat{x}_{2}=\theta_{T} \cdot \pi$,

where $\theta_{\mathrm{T}}$ is the fraction of aggregate national income represented by activity in the Input Tier. At fixed proportions, $\hat{x}_{0}=\hat{x}_{1}=\hat{x}_{2}=$ $\theta_{T} \pi$ and the wage rate must rise by enough so that, from the labor constraint, (5),

$$
\hat{x}_{0}=-\left\{\lambda_{L 1} \hat{a}_{L 1}+\lambda_{L 2} \hat{a}_{L 2}\right\}=\delta_{L} \hat{w}
$$

Therefore technical progress can be passed onto increased proportional outputs of the two sectors in the Output Tier with overall full employment of labor and no inter-tier reallocation only if

$$
\hat{\mathrm{W}}=\frac{{ }^{\theta} \mathrm{T}}{\delta_{\mathrm{L}}} \pi \text {. }
$$

As in our preceding discussion of the tariff, labor reallocates between tiers until the wage rate is equated, and this requires $\hat{\mathrm{w}}$ to equal a weighted average of the value it would have in each tier prior to reallocation. Following the procedure leading to equation (17) for tariff changes,

(28) $\hat{\mathrm{w}}=n \pi \quad$ where $\eta \equiv\left\{\alpha_{I} \cdot 1+\alpha_{0} \cdot \frac{\theta_{T}}{\delta_{L}}\right\}$

and $\alpha_{I}$ and $\alpha_{0}$ are the weights defined in equation (17). Labor would in this case gain, and by an amount exceeding the degree of productivity improvement if $\theta_{\mathrm{T}} / \delta_{\mathrm{L}}$ exceeds unity. To see what this entails, note that

$$
\theta_{\mathrm{T}} \equiv \theta_{1} \theta_{\mathrm{Al}}+\theta_{2} \theta_{\mathrm{B} 2}
$$

whereas

$$
\delta_{\mathrm{L}} \equiv \lambda_{\mathrm{L} 1}{ }_{\mathrm{A} 1}{ }^{\sigma_{1}}+\lambda_{\mathrm{L} 2}{ }_{\mathrm{B} 2} \sigma_{2} \text {. }
$$




$$
\mathrm{IV}-5
$$

Clearly low values of the elasticities of substitution in the two sectors favor labor, for in such a case the labor required for extra output in the Output Tier must be drawn from the Input Tier (since a rise in w by itself does not release much labor).

Critical values for the elasticities of substitution can be obtained if sectoral parity is assumed in the sense that $\sigma_{i}=\sigma_{1}=\sigma_{2}$. If $x_{1}$ is 1abor-intensive, $\theta_{A 1}$ falls short of $\theta_{B 2}$ and $\lambda_{L 1}$, which weights $\theta_{A 1}$ in $\delta_{L}$, must exceed $\theta_{1}$, which weights $\theta_{A 1}$ in the expression for $\theta_{\mathrm{T}}$. In such a case $\theta_{\mathrm{T}} \cdot \sigma_{i}$ clearly exceeds $\delta_{\mathrm{L}}$. (If $x_{2}$ is labor-intensive the same conclusion emerges since $\theta_{\mathrm{A} 1}>\theta_{\mathrm{B} 2}$ but $\theta_{1}>\lambda_{I_{1}}$.) Therefore if elasticities of substitution fall short of unity, the wage rate rises by more than the productivity improvement and labor is withdrawn from the Input Tier. This, in turn, requires the real incomes of both factors specifically used in the Input Tier to rise by less than the uniform productivity improvement. Indeed, from the competitive profit conditions in the Input Tier for sector $j(j=A, B)$,

$$
\theta_{L j} \hat{w}+\theta_{V j} \hat{r}_{j}=\pi
$$

a relative wage rise that exceeds $\pi / \theta_{L j}$ (the Harrod measure) would reduce the nominal income of specific factor $j$. Since both $p_{1}$ and $\mathrm{p}_{2}$ rise (as wages rise), real income of factor $\mathrm{v}_{\mathrm{j}}$ would unambiguously fall.

The general solution for $\hat{w}$, when consumers respond in a finite fashion to a change in relative prices of final goods, as in demand equation (18), can be obtained by comparing (18) (with the solution $|\theta| \hat{w}=\left(\hat{p}_{1}-\hat{p}_{2}\right)$ inserted $)$ with the solution for $\left(\hat{x}_{1}-\hat{x}_{2}\right)$ derived by subtracting (27) from (7). Using the weights already defined, (29) $\frac{\hat{\mathrm{W}}}{\pi}=\kappa_{0} \eta+\kappa_{\infty} \cdot 0$. 


$$
\text { IV }-6
$$

That is, in general uniform technical progress in the Input Tier raises the nominal wage somewhat, by larger amounts the more resistant are consumers to changes in relative output proportions. The real wage must also rise since the wage rise is the only cost component of increases in final output prices. Real incomes of the specific factors can be expected to rise unless the wage increase exceeds the productivity increase by an amount proportional to the inverse of labor's share in sectors of the Input Tier. The required reallocation of labor between the two tiers is linked uniquely to the comparison of the wage change and the productivity rise.

The case in which uniform Hicksian productivity increases take place in the output Tier is easier to analyze. At one extreme, if $\mathrm{p}_{1} / \mathrm{p}_{2}$ remains constant (the case of linear indifference curves), the wage rate cannot change in nominal terms since the pair of equations,

$$
\begin{aligned}
& \theta_{L 1} \hat{\mathrm{w}}=\pi+\hat{\mathrm{p}}_{\mathrm{O}} \\
& \theta_{\mathrm{L} 2 \mathrm{w}}=\pi+\hat{\mathrm{p}}_{\mathrm{O}}
\end{aligned}
$$

can only be satisfied if the right-hand side is zero. That is, uniform Hicksian improvement in the Output Tier that is not allowed to change relative output prices must reduce absolute output prices proportionally to the productivity increase. Labor unambiguously gains in real terms, but in its role as consumer. Indeed all primary factors gain in real terms by the same amount since no nominal factor prices change.

This kind of technical progress in the Output Tier uniformly expands the transformation schedule. Thus regardless of the value of the demand substitution elasticity, $\sigma_{D}$, outputs expand propor- 


$$
\text { IV }-7
$$

tionally as long as demand is homothetic. Relative output prices, $\mathrm{p}_{1} / \mathrm{p}_{2}$, are not disturbed. On the pricing front all factor prices (as well as prices of traded middle products given from the outside) remain constant in nominal terms, no labor is reallocated between the two tiers or between sectors in either tier, and the productivity improvement is reflected in a uniform reduction in prices of both non-tradeable final commodities. 


\section{The Transfer Problem}

One of the classic questions in the literature on trade theory asks how adjustment is made to a required transfer of purchasing power from one country to another. Most models agree on the necessity of a drop in real spending (or real income) in the transferor, coupled with a fall in the relative price of non-tradables, and increases in both these variables in the recipient country. The terms of trade, however, can move either in favor of the transferee (the "orthodox" result) or in favor of the transferor (the "anti-orthodox" result), with presumption in one direction or the other rooted in large part in the-underlying causes-of trade. 10 The model of trade in middle products adds relatively little to the analysis of the commodity terms of trade, but does provide a strong argument for the deterioration of the factoral terms of trade in the country required to make the transfer. In what follows we examine only the impact effect of a transfer at given commodity terms of trade on the transferor country, thus sidestepping the necessity of solving for world-determined prices of middle products.

The initial equilibrium in the Output Tier is shown by point $\underline{\mathrm{C}}$ in Figure 10, where the $\mathrm{L}_{0}$ and $\mathrm{T}$ constraints intersect. (The transformation curve in the Output Tier is the dotted locus through point $($ ) $)$. The impact of a transfer on these constraints depends in part on whether the wage rate must adjust to clear local markets. Suppose, initially, no re-allocation of labor between tiers is required so that the wage rate is constant. In terms of Figure 1, a transfer of specified amount (in terms of world prices for middle products) is effected by the country's running a trade surplus of

10) For a summary of these results see Jones, [3], Chapter 10. 


$$
V-1 a
$$

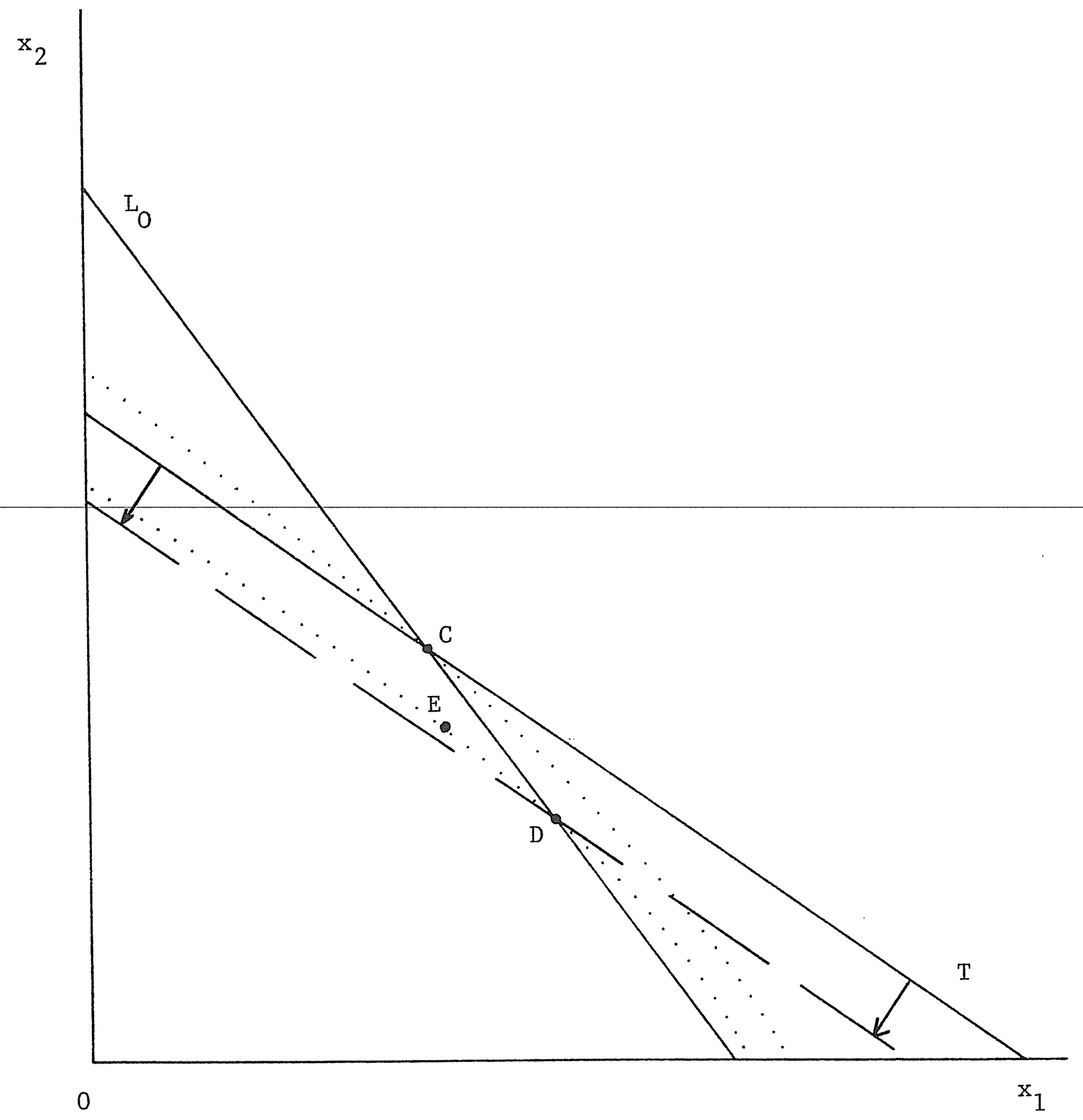

Figure 10 
this given amount; the consumption point, $\underline{H}$, would now lie on a line closer to the origin (by the amount of the surplus) while production remains at $\mathrm{J}$. "This implies that the T-constraint line in Figure 10 shifts towards the origin and production moves from $\underline{C}$ to $\underline{D}$. That is, the transfer causes the Output Tier's transformation schedule to shift in towards the origin, such that at given relative output prices more of the labor-intensive commodity is produced, balanced by a fall, of even greater amount in value, in the output of the commodity intensive in its use of traded middle products.

The move from $\underline{C}$ to $\underline{D}$ in Figure 10 would be tolerated by consumers only if indifference curves were straight lines. If so, the transfer calls for a fall in aggregate spending on final-nontraded commodities, with no change in the distribution of earned income being required. Nor, for that matter, do any prices of final commodities change. However, if consumers resist the substitution of $x_{1}$ for $x_{2}$ involved in the move from $\underline{C}$ to $\underline{D}$, as they would with smoothly bowed-in indifference curves, the relative price of the labor-intensive non-tradeable $\left(\mathrm{p}_{1} / \mathrm{p}_{2}\right)$ must fall. This causes the wage rate to fall and pushes labor into the Input Tier. In Figure 10 this labor reallocation causes the $\mathrm{L}_{0}$-constraint to move in (both because $\mathrm{L}_{0}$ falls and because more labor-intensive techniques are adopted) and the T-constraint to shift out towards a new intersection at some point such as $\underline{E}$.

In some ways the economy of the transferor country adjusts to a transfer in just the opposite way as would a country experiencing technical progress (of a uniform Hicksian variety) in the Input Tier. The case of technical progress involved an expansion of the Output Tier's transformation schedule, whereas a transfer 
causes this schedule to shift in. But in each case this shift is strongly biased; before any labor reallocates only the Tconstraint shifts. In Figure 9's depiction of technical progress the increased availability of traded middle products is the source of the expansion of non-tradeables, but in such a biased way that at constant prices output of labor-intensive non-tradables would fal1 (from $\underline{C}$ to $\underline{D}$ in Figure 9). Figure 10 shows the reverse a fall in the T-constraint as the transfer requires a current account surplus measured in a cut in middle products available locally as inputs to the Output Tier. But this cut leads to a biased alteration of outputs typical of the magnification effect; labor-intensive $x_{1}$ actually rises (from $\underline{C}$ to $\underline{D}$ in Figure 10). The two situations admittedly differ in that the case of technical progress shown in Figure 9 has a movement of labor to the Input Tier (and consequent further outward shift in the T-constraint) in order to keep the wage rate constant (as it must be at a constant $\mathrm{p}_{1} / \mathrm{p}_{2}$ ratio). This results in an even more pronounced output bias towards the commodity intensive in its use of middle products (from $\underline{D}$ to $\underline{E}$ in Figure 9 ).

The next stage of the argument reveals the crucial role of demand, even for a small country which is a price taker for traded middle products. If indifference curves for final products are bowed in, the biased changes in the Output Tier's transformation schedule described above require a corresponding alteration in relative output prices in order that markets clear. In the case of technical progress the relative price of contracting laborintensive products must rise, whereas in a country required to make 
a transfer, the relative price of expanding labor-intensive products would fall. It is these price changes which force an accomodation in the wage rate via the typical Heckscher-Ohlin process. Wage rate alterations, in turn, cause inter-tier labor reallocations and changes in the intensities with which labor and middle products are employed. In the case of transfer these further changes cause outputs to move from $\underline{\mathrm{D}}$ to $\underline{\mathrm{E}}$ in Figure 10 as wages fall. (Such changes are not shown for the case of technical progress in Figure 9, but would involve a movement southeast of $\underline{E}$ along the new transformation schedule as wages rise.)

To conclude, a transfer must lower wages in the transferor country and raise them in the recipient country - the transferor suffers a deterioration in the (double) factoral terms of trade, Furthermore, in each country the wage rate change is more drastic than the change in final consumer prices since trade converts the Output Tier into the standard two-by-two productive structure. That is, the real wage unambiguously falls in the transferor and rises abroad. 11

11) In the traditional two-commodity (tradeables and non-tradeables) specific-factors model, a transfer depresses the local price of non-tradeables, but not necessarily the real wage. It would be necessary to compare fractions such as $\beta_{A}$ (equation (2)) with the share of income workers spend on each commodity. For details see Ruffin and Jones, [7]. 


\section{Devaluation}

The preceding analysis of the transfer problem provides a useful introduction to the issue of devaluation. A key difference, however, is that the size of the surplus (or deficit) is not arbitrarily given, as in the transfer story. Instead, it depends on the real structure of the model as we11 as upon monetary or asset market behavior which we now describe. ${ }^{12}$

Suppose the economy is at an initial full equilibrium in which the aggregate monetary value of expenditures, $\underline{Z}$, equals precisely the aggregate value of national income produced, $\underline{Y}$. This, of course, implies a-balance in the trade-account. Suppose also that corresponding to this flow of income and expenditures there exists a level of assets of the appropriate composition, depending on the specification of asset demand and its link to income levels. The basic hypothesis we employ is that an increase in the monetary value of produced income causes a specified immediate increase in the monetary value of expenditures, but of a smaller magnitude. This hypothesis is captured by equation (30), (30) $\hat{\mathrm{Z}}=\xi \hat{\mathrm{Y}} \quad$ where $0<\xi<1$, and is consistent with a variety of more detailed hypotheses as to asset behavior. If, as we assume, the domestic supply of securities and money is taken as fixed, any increase in the monetary value of income must eventuate in a trade surplus, which is utilized in some fashion to increase the locally held supplies of money and/or securities.

Both aggregate income and aggregate expenditure have real and price level components. The change in the price level appropriate to both aggregates if expenditures initially equal incomes is shown by $\hat{\mathrm{P}}$ :

12) This behavior is discussed in more detail in Noman and Jones, [6]. 
(31) $\hat{\mathrm{p}}=\theta_{1} \hat{\mathrm{p}}_{1}+\theta_{2} \hat{\mathrm{p}}_{2}$.

In the case of a small country, devaluation brings about the same proportional rise in the prices of all traded middle products. Let $\hat{\mathrm{p}}_{\mathrm{T}}=\hat{\mathrm{p}}_{\mathrm{A}}=\hat{\mathrm{p}}_{\mathrm{B}}$. By the profit conditions of competitive equilibrium set out in (11) and (12), aggregation over the Output Tier yields (32) as the cost-explained change in the price level:

(32) $\hat{\mathrm{P}}=\theta_{\mathrm{LO}} \hat{\mathrm{W}}+\theta_{\mathrm{T}} \hat{\mathrm{P}}_{\mathrm{T}}$.

Breaking down expenditures and incomes into real and price level components,

(33) $\hat{\mathrm{Z}}=\hat{z}+\hat{\mathrm{P}}$,

(34) $\hat{\mathrm{Y}}=\hat{\mathrm{y}}+\hat{\mathrm{P}}$.

With full employment of a fixed aggregate labor supply and no change in the terms of trade, real output remains constant. Therefore substitution of (33) and (34) into (30) yields:

(35) $\hat{z}=-(1-\xi) \hat{P}$.

That is, the relative change in real expenditures, equal to $\left\{\theta_{1} \hat{x}_{1}+\theta_{2} \hat{x}_{2}\right\}$, is negative if the price level rises, by a proportion which indicates how speedily the economy wishes to adjust to a new asset-equilibrium position by cutting expenditures below current income levels. The cut in real expenditures is also proportional to the rise in the price level which, since it depends partly on wages, is endogenously related to the real structure of the model. Turning immediately to the general case in which substitution elasticities in demand may lie anywhere between zero and infinity, consider the change in the constraint on labor supply to the Output 
Tier., Since devaluation causes $\hat{\mathrm{p}}_{\mathrm{A}}$ and $\hat{\mathrm{p}}_{\mathrm{B}}$ each to equal $\hat{\mathrm{p}}_{\mathrm{T}}$, the general form of (5) reduces to:

$$
\lambda_{L 1} \hat{x}_{1}+\lambda_{L 2} \hat{x}_{2}=\hat{\mathrm{L}}_{0}+\delta_{L}\left(\hat{\mathrm{w}}-\hat{\mathrm{p}}_{\mathrm{T}}\right)
$$

By equation (2) $\hat{w}$ equals $\left\{\hat{\mathrm{p}}_{\mathrm{T}}-\frac{1}{\gamma_{I}} \hat{\mathrm{L}}_{\mathrm{I}}\right\}$ so that $\hat{\mathrm{L}}_{\mathrm{O}}$ is shown by:

$$
\hat{\mathrm{L}}_{\mathrm{O}}=\frac{\lambda_{\mathrm{LI}} \gamma_{I}}{\lambda_{\mathrm{LO}}}\left(\hat{\mathrm{w}}-\hat{\mathrm{p}}_{\mathrm{T}}\right)
$$

(This reveals that if the wage rate does not manage to rise by the extent of the devaluation, 1 abor will be reallocated from the Output Tier to the Input Tier.) Therefore the shift in the $\mathrm{L}_{\mathrm{o}}$-constraint line-is-shown-by-equation-(36),

(36) $\lambda_{L 1} \hat{x}_{1}+\lambda_{L 2} \hat{x}_{2}=\omega\left(\hat{w}-\hat{p}_{T}\right)$, where once again $\omega$ captures the shift in the labor constraint line in the Output Tier, $\left\{\frac{\lambda_{L I} x_{I}}{\lambda_{L o}}+\delta_{L}\right\}$, that comes both from factor substitution within the Output Tier and inter-tier labor reallocation. The other relationship determining output changes on the supply side is provided by (35), rewritten, with the help of (32), as:

$$
\theta_{1} \hat{x}_{1}+\theta_{2} \hat{x}_{2}=-(1-\xi)\left\{\theta_{L O} \hat{w}+\theta_{T} \hat{p}_{T}\right\}
$$

The procedure to determine the impact of devaluation on the wage rate now follows the pattern set out in earlier sections. Subtracting (37) from (36) yields:

$$
\theta_{T}|\lambda|\left(\hat{x}_{1}-\hat{x}_{2}\right)=\left\{\omega+(1-\xi) \theta_{L 0}\right\} \hat{w}-\left\{\omega-(1-\xi) \theta_{T}\right\} \hat{p}_{T} \cdot
$$

This change in the composition of outputs of non-traded goods must be matched by the demand change shown in (18). First substitute the relationship between factor prices and commodity prices in the Output Tier, 


$$
|\theta|\left(\hat{w}-\hat{p}_{T}\right)=\left(\hat{p}_{1}-\hat{p}_{2}\right)
$$

to obtain (40) as the demand term:

(40) $\theta_{T}|\lambda|\left(\hat{x}_{1}-\hat{x}_{2}\right)=-\theta_{T}|\lambda||\theta| \quad \sigma_{D}\left(\hat{w}_{-}-\hat{p}_{T}\right)$.

Finally, $\hat{\mathrm{w}}$ is linked to $\hat{\mathrm{p}}_{\mathrm{T}}$ by equating demand and supply in (38) and $(40)$ :

(41) $\hat{\mathrm{w}}=\frac{\left\{\omega+\theta_{T}|\lambda||\theta| \sigma_{\mathrm{D}}-(1-\xi) \theta_{T}\right\}}{\left\{\omega+\theta_{T}|\lambda||\theta| \sigma_{D}+(1-\xi) \theta_{L 0}\right\}} \hat{\mathrm{p}}_{\mathrm{T}}$.

If demand for non-tradeables were so elastic as to keep the $\mathrm{p}_{1} / \mathrm{p}_{2}$ price ratio from changing, a devaluation would serve to raise all factor prices by the same proportional amount. The price level would also rise by this same amount, a surplus in the trade account would be created, but no reallocation of labor between tiers is required. However, if the implied cut in the output of $\mathrm{x}_{2}$ and rise in output of labor-intensive $x_{1}$ at constant $\mathrm{p}_{1} / \mathrm{p}_{2}$ is resisted by consumers (because $\sigma_{D}$ is finite), $\mathrm{p}_{1} / \mathrm{p}_{2}$ must fall and, as (41) shows, this must lower the wage rate relative to the higher prices for middle products. This cut in relative wages is, of course, associated with a transfer of labor to the Input Tier which produces tradeables, as well as to a change towards more labor-intensive techniques in producing both non-tradeables. Labor is the clear loser with devaluation. Factor proportions in the Output Tier dictate the composition of the reduction in aggregate output as a trade surplus is created. If commodity 1 is labor-intensive, $\mathrm{p}_{1}$ falls by more than $\mathrm{p}_{2}$ (relative to higher $\mathrm{p}_{\mathrm{T}}$ ), whereas if commodity 2 is labor-intensive, $\hat{\mathrm{p}}_{2}<\hat{\mathrm{p}}_{1}<\hat{\mathrm{p}}_{\mathrm{T}}$. In either case the wage rate rises by less than either price of the commodities 


$$
\mathrm{VI}-5
$$

consumed by labor. And factors specifically used in the Input Tier clearly gain by devaluation: both $r_{A}$ and $r_{B}$ rise more than $p_{T}$ (and therefore more than $\mathrm{p}_{1}$ and $\mathrm{p}_{2}$ ).

It is even possible that a currency devaluation will lower the wage rate in nominal terms as well as real terms. As equation (41) shows, this is more likely the lower is $\sigma_{D}$, for that implies, as well, a greater relative drop in the price of whichever commodity is labor-intensive in the Output Tier. At the limit, if $\sigma_{D}$ is zero, the numerator of (4) becomes negative if $\omega$ is smaller than $(1-\xi) \theta_{T}$ ? a fraction. But small elasticities of factor substitution in all four productive sectors can make $\omega$ as small as required for any value of $(1-\xi) \theta_{T}$. With currency devaluation, inelasticity in demand and supply both tend to harm labor during the adjustment process, since they both contribute to a more severe drop in the relative price of the labor-intensive final consumption good. 


\section{Possible Extensions}

The model of trade in middle products analyzed in detail in preceding sections perhaps seems complicated enough that little temptation remains to make further extensions. Without going into much detail, there are two areas in which extensions can be contemplated fairly easily.

\section{A. The Case of Raw Materials}

It is possible to argue that raw materials differ from general middle product inputs in possessing little scope for substitution with labor or other inputs. That is, different techniques, requiring different proportions of productive factors and intermediate product inputs, are typically associated with constant requirements of raw materials per unit of output.

If middle products $\underline{A}$ and $\underline{B}$ are considered to be raw materials with fixed coefficients, the Output Tier becomes Ricardian in the sense that labor does not substitute with other inputs to produce final commodities. However, the Output Tier's transformation schedule remains smoothly bowed out since the quantity of labor allocated to the Output Tier steadily increases as the composition of final goods output is varied in favor of the labor-intensive good. This serves smoothly to drive up the wage rate and, through this means, to change the relative costs of producing the two final commodities. In our preceding analysis terms such as the $\sigma_{i}$ and $\delta_{L}$ vanish but the qualitative nature of the results is unchanged.

Allowing for factor substitution when middle products are raw materials is possible by introducing specific factors in the Output Tier as we1l as the Input Tier. Indeed, the raw materials case allows us to obtain some insight into the significance of our earlier neglect of specific factors in the Output Tier. We 
proceed only a few steps in developing the model, to show both that our earlier results are robust and that the key interpretation of factor-intensity conditions involves middle products and all other factors as an aggregate rather than a direct comparison of labor-intensities.

Figure 11 illustrates the argument. A given initial allocation of labor between tiers again delimits two constraints on final outputs. The constraint provided by the balance of trade at given world prices is the same as earlier forms of the T-constraint. The $L_{0}$-constraint is now different. It represents the locus of final outputs that could be produced with $\mathrm{L}_{\mathrm{o}}$ and the given amounts of specific factors, $V_{1}$ and $V_{2}$, ignoring the constraint which raw materials (middle product) requirements place upon final outputs. It is bowed out for the same reason that the Input Tier's schedule (Figure 1) is bowed out. The crucial comparison is between the slopes of the two constraints at initial equilibrium point, $\underline{C}$. In drawing the $\mathrm{T}$-constraint flatter than the $\mathrm{L}_{\mathrm{o}}$-curve, we have assumed that final commodity $x_{1}$ has a lower fraction of its revenue devoted to middle products than does $x_{2}$. It may or may not be labor-intensive in the sense of labor's having a higher distributive share in $x_{1}$ than in $x_{2}$. What counts is the comparison of middleproduct use with that of all other factors. An attempt to expand $\mathrm{x}_{1}$ output beyond the level shown at point $\underline{\mathrm{C}}$ reveals that with the given allocation of labor between tiers excess supplies of raw materials would be available. That is, labor can be released from the Input Tier, causing the T-constraint to shift in but allowing the $L_{0}$ (or really $L_{0}$ plus $V_{1}$ plus $V_{2}$ )-constraint to shift out. A point such as $\underline{D}$ matches raw materials requirements with the necessary supplies of labor and specific factors in the Output 


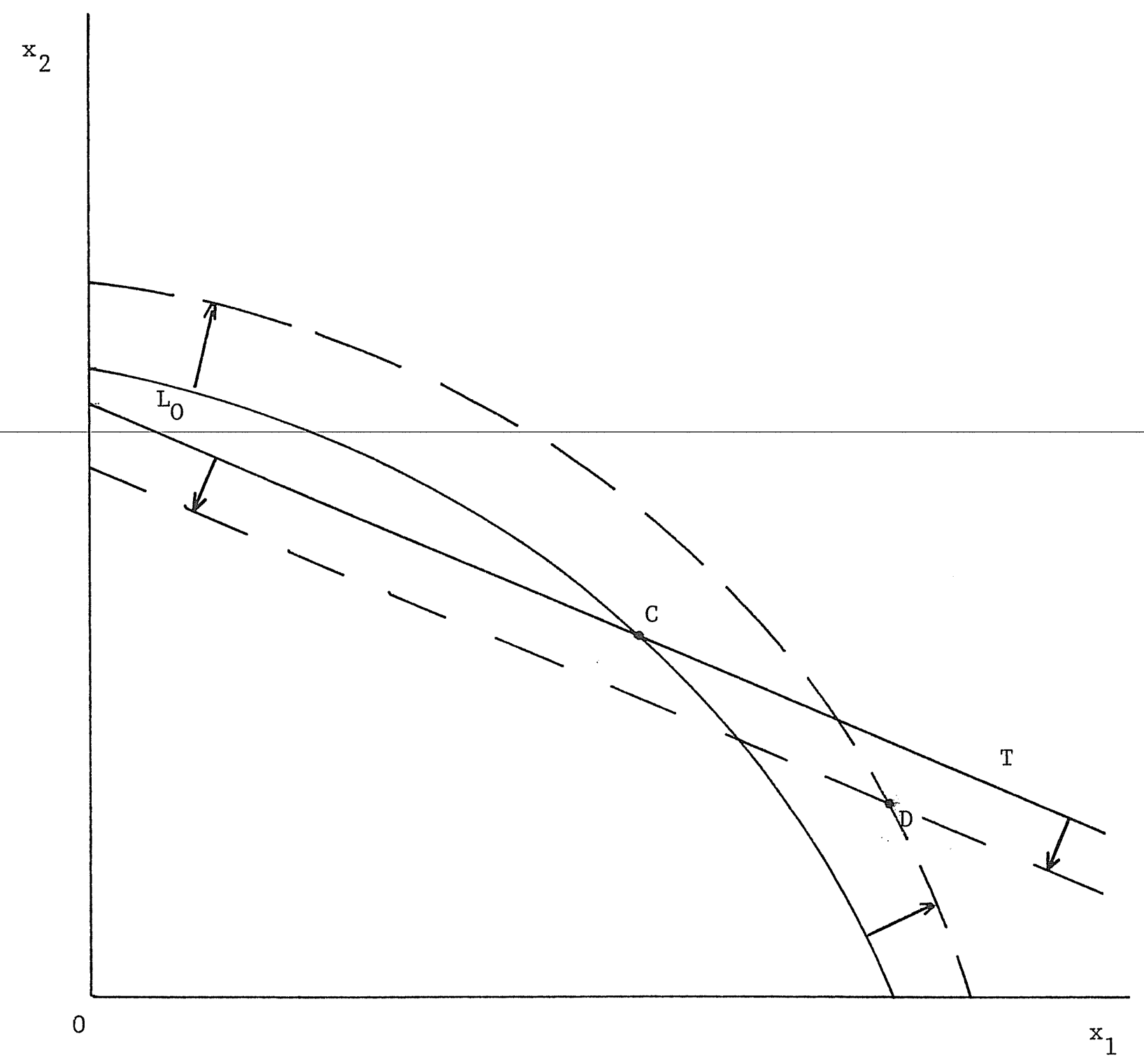

Figure 11 
Tier. The Output Tier's transformation schedule passes through points like $\underline{C}$ and $\underline{D}$ and, as more of the commodity $\left(\mathrm{x}_{1}\right)$ unintensive in its use of traded raw materials is produced, the wage rate is driven up.

More formally, output movements and wage rate changes can be linked by considering changes along the transformation schedule,

$$
\theta_{1} \hat{x}_{1}+\theta_{2} \hat{x}_{2}=0
$$

and output changes along the (shifting) T-constraint

$$
\lambda_{\mathrm{T} 1} \hat{\mathrm{x}}_{1}+\lambda_{\mathrm{T} 2} \hat{\mathrm{x}}_{2}=\hat{\mathrm{T}}
$$

This latter constraint is more simple than the earlier form in equation (8) because traded raw materials bear a fixed coefficient relationship to outputs. Now $\hat{T}$ equals $\theta_{L I} \hat{\mathrm{L}}_{I}$, which, by (2) with fixed raw materials prices, equals $-\theta_{L I} \gamma_{I} \hat{w}_{\text {. }}$ Subtraction yields (42):

$$
\left(\theta_{1}-\lambda_{T 1}\right)\left(\hat{x}_{1}-\hat{x}_{2}\right)=\theta_{L I} \gamma_{I} \hat{w}
$$

The point to stress about this relationship is that the required reallocation of labor between tiers (and the corresponding change in the wage rate) as the composition of final outputs changes depends not upon labor intensities but upon a comparison of the intensities with which traded middle products (raw materials) are used. To see this note that the ratio $\lambda_{\mathrm{T} 1} / \theta_{1}$ is the same as the ratio $\theta_{\mathrm{A} 1} /\left(\theta_{1} \theta_{\mathrm{A} 1}+\theta_{2} \theta_{\mathrm{B} 2}\right)$. That is, the first industry claims a smaller fraction of traded middle products than is represented by its share of final output $\left(\lambda_{\mathrm{T} 1}<\theta_{1}\right)$ if and only if the share of middle products in total costs in the first industry falls short of its share in the second (and therefore in a weighted average of $\theta_{\mathrm{A} 1}$ and $\left.\theta_{\mathrm{B} 2}\right)$. The first industry might also have a smaller labor share $\left(\theta_{\mathrm{L} 1}<\theta_{\mathrm{L} 2}\right)$ if specific factor use in the first industry is 


\section{VII -4}

important enough. But the labor movement between tiers depends only upon middle product shares. The slope comparison at $\underline{C}$ in Figure 11 involves middle product use versus all other factors. But of these other factors, only labor is mobile between tiers.

\section{B. Many Commodities}

This model of trade in middle products proves robust in terms of the number of commodities produced in both tiers of the economy. In the Input Tier any number of specific factors can each be combined with labor to produce traded middle products - the structure of the specific factors model has been shown to generalize in its important characteristics to any number of sectors. ${ }^{10}$ In addition, with trade the economy need not produce a wide variety of middle products. The number of traded middle products serving as inputs to the Output Tier may exceed by a large measure the number of middle products locally produced.

Relationships in the Output Tier are also simple if labor is the only factor of production combined with middle product inputs. Indeed, it is also possible to relax the assumption that each middle product is used specifically to produce a single non-traded final commodity. Instead, middle products may enter as inputs into a variety of final products. Again, it is the existence of trade with prices determined from outside that allows the simplifications possible in a two-factor model. For each final non-traded commodity produced the crucial technological datum is the share in total costs represented by (all) middle product inputs. Retaining the assumption that labor is the only non-traded input in the Output Tier, the economy's transformation surface is 13) See the discussion in Jones, [2]. 
ruled. Tastes for final commodities resolve any hint of indeterminacy. A change of tastes, or a change in the terms of trade, will in general alter the wage rate and thus the entire structure of relative prices depending upon factor intensities in the output Tier. 


\section{Concluding Remarks}

The central feature of this model has been the location of international trade in the middle of a nation's productive spectrum instead of at the end. This necessitates breaking productive activity into Input and Output Tiers, where the link between the two is provided both by the mobility of labor and the balance of trade constraint. Although the basic productive structure in both tiers is that of a specific-factors model, the existence of trade at given world prices in the inputs of the Output Tier allows these specific-factor inputs to be aggregated into a composite traded input and converts the structure of the Output Tier into the familiar two-factor (labor and middle products) HeckscherOhlin model. 14

With all final consumer goods incorporating at least some local (labor) value added, the relative prices of final commodities will depend in part on domestic taste patterns even for a small country. Crucial in the model is the extent to which consumers are willing to substitute between final goods in response to a change in relative prices. In general both output response and changes in income distribution depend upon the weight which each of two extreme prototypes receives: the case of zero substitutability in demand and the case of infinite substitutability (so that relative output prices are fixed). The former extreme leads to changes in income distribution reminiscent of specific factor models. For example, a tariff on importables leaves real wages relatively unaltered, regardless of the pattern of trade. By contrast, the case of fixed relative output prices leads to factor returns linked in a magnified fashion to changes in world prices of middle products,

14) As Douglas Purvis remarked about this model: 'Heckscher-Ohlin does not explain trade; trade explains Heckscher-Ohlin.' 
depending on factor intensities in the Output Tier as in a HeckscherOhlin model.

As our discussion of the case of raw materials illustrated, the key feature of factor-intensity ranking in the Output Tier is a comparison between shares of traded middle-products inputs in each sector, even if other non-traded specific factors (as well as mobile labor) are used as inputs. As output composition is varied in favor of the industry with the larger share of traded middle products in value added, more middle products must be produced in the Input Tier, and the only way this can be accomplished is via a reallocation of labor to the Input Tier, with a consequent harmful effect on real wages.

A stylized fact often cited in contrasting trade patterns of less developed nations with that of developed economies points to the tendency of LDC exports to be dominated by raw materials and unfinished or semi-finished intermediate goods or manufactures. Whatever truth is contained in such a contrast, it is a feature of the trading pattern that is captured in this model. Middle products at early stages of the productive spectrum are precisely those items which require relatively large amounts of local value added in the Output Tier. That is, there may be a systematic bias towards LDC exports being used as inputs in the laborintensive (or middle-product-unintensive) sector in the Output Tier.

To the extent that such a consistent bias exists, the model indicates that the attitude of labor towards a favorable movement in the terms of trade (or towards protection) should differ systematically between LDC and developed regions. In developed regions an improvement in the terms of trade both helps the nation 


\section{VIII - 3}

overall and, to the extent that its higher priced exports are used as inputs into the middle-product-intensive industry, helps to raise real wages. This harmony of interests between labor and the overall economy would be absent in LDC's, for whom an improvement in export prices (where exportables are used as inputs in labor-intensive sectors) would tend to lower real wages (and benefit factors specifically employed in the Input Tier). The model of trade in middle products developed in this paper seems suited to analyzing the consequences of any such asymmetries in nations' trading patterns. And, in contrast to more simple models of trade, the present model points to the importance of factor proportions in the industries using traded middle products as opposed to the industries producing them. 


\section{References}

[1] Caves, R. E. and R. W. Jones, World Trade and Payments: An Introduction, Revised Edition (Little, Brown, 1977).

[2] Jones, R. W., "Income Distribution and Effective Protection in a Multi-Commodity Trade Mode1", Journal of Economic Theory, August, 1975.

[3] Jones, R. W., International Trade: Essays in Theory, North-Holland, 1979.

[4] Jones, R. W., "Demand Behavior and the Theory of International Trade", in J. S. Chipman and C. P. Kindleberger eds, Flexible Exchange Rates and the Balance of Payments (North-Holland, 1980).

[5] Mayer, W., "Short-run and Long-run Equilibrium for a Sma11, Open Economy", Journal of Political Economy, October, 1974.

[6] Noman, K. and R. W. Jones, "A Mode1 of Trade and Unemployment", in Green, J. and J. Scheinkman, eds, Genera1 Equilibrium, Growth and Trade (Academic Press, 1979).

[7] Ruffin, R. and R. W. Jones, "Protection and Real Wages: The NeoClassical Ambiguity", Journal of Economic Theory, Apri1, 1977. 